\title{
Aymaras entre Bolivia, Perú y Chile
}

Xavier Albo C. '

\section{RESUMEN}

Se repasa la historia del pueblo aymara, enfatizando lo común y lo diferente de acuerdo a sus experiencias en alguno de los tres estados republicanos. Al final se subrayan aquellos aspectos en que más se fortalece la identidad común de la nación aymara a un lado u otro de estas fronteras estatales.

\section{ABSTRACT}

This paper goes through the history of the Aymara people, emphasizing the commonalties and differences according to its experiences in some of the three republican countries. At the end, those aspects which strengthen the common identity of the Aymara nation at either side of these state borders are underlined.

\section{Introducción}

Las fronteras de nuestros estados modernos se hicieron y deshicieron sin contar con la perspectiva, la opinión ni menos el consenso de los pueblos originarios cuyos territorios cruzan y a los que parten entre dos o más estados, constituidos sin ellos. Los efectos que éstas producen en la sobrevivencia de determinados pueblos son tan graves y a veces tan irreversibles, que uno hasta se sentiría tentado a pensar que hubo cierta intencionalidad de los estados-nación al trazarlas. No sabemos si hay o no base para tal sospecha en el pasado. Pero, para despejarla totalmente en el futuro, es oportuno señalar los efectos de esta situación, para minimizar sus consecuencias negativas principalmente en estos tiempos en que la mayoría de los estados están introduciendo cambios en su legislación para reconocer, en mayor o menor grado, su carácter multiétnico y pluricultural.

Ninguno de estos ajustes jurídicos ha tenido hasta ahora la audacia de plantear la posibilidad de un

1 CIPCA, Bolivia.

Casilla 283, La Paz. E-mail: xalbo@caoba.entelnet.bo estado "plurinacional", aunque varios se reconocen ya desde su fundación como "estados unidos" federativos. La CPE que más ha avanzado en esta línea es la del Ecuador, aprobada en 1998, que inicia su enumeración de los derechos indígenas con la solemne frase: "Los pueblos indígenas, que se autodefinen como nacionalidades de raíces ancestrales" (art. 83). En este mismo espíritu podríamos hablar aquí de "nación aymara" o, en general, de "naciones étnicas" como una categoría por la que, sin negar su pertenencia a determinadas naciones-estado, estos pueblos siguen también reclamando para sí el rango de nación y redefinen su utopía de Estado como "estado plurinacional". Pero, cuando planteamos este tema a un nivel "inter-estatal" el concepto resulta todavía más complejo y audaz: ¿Podemos soñar además en una nación étnica que se consolide a través de dos o más fronteras estatales sin que por ello sus miembros dejen a la vez de sentirse ciudadanos de una u otra naciónestado?

Nos limitamos aquí a tratar en detalle el caso de la nación o pueblo aymara, aunque no es el único que atraviesa las fronteras de Bolivia, Perú o Chile. Pensemos en los pueblos guaraní, mapuche o quechua. Dado nuestro énfasis teórico, nos concentraremos sobre todo en mostrar aquellos procesos socioeconómicos, políticos e ideológicos que puedan arrojar alguna luz sobre la pregunta anterior, sin entrar al detalle de analizar los contenidos concretos de la cultura aymara en uno u otro contexto estatal. Después de ofrecer al lector un mínimo de datos básicos, haremos un recuento sumario de la evolución del pueblo aymara de acuerdo a la historia social y política de cada país, enfatizando las comparaciones y relaciones que a lo largo de ella ocurren entre los tres países. Al final, a la luz de esta información, nos replantearemos la pregunta que hemos lanzado más arriba.

\section{Los datos básicos}

Actualmente el aymara es el tercer idioma indoamericano más hablado en todo el continente, 
con un total de dos millones largos de hablantes, cifra superada sólo por el quechua y el guaraní, distribuidos sobre todo en tres países: Bolivia, Perú y Chile. Su área principal es el occidente central de la actual Bolivia (con aproximadamente 1,7 millones de hablantes) y las regiones colindantes del Perú, al norte y sur del lago Titicaca (medio millón de hablantes) y en el extremo noreste de Chile (unos 20.000 hablantes). En cada uno de los tres países el aymara es la segunda lengua y etnia más numerosa, después de la quechua --en Bolivia y Perú-- y de la Mapuche --en Chile--. Resulta particularmente difícil trazar en detalle la frontera occidental del territorio aymara, hacia el océano Pacífico, tanto en el Perú como en Chile, porque en esta parte existe menos información linguística y, por otra parte, el idioma resulta menos útil para definir la identidad étnica, pues se ha perdido bastante sin que ello sea óbice para que parte de la población siga identificándose como aymara. En las ciudades costeñas --Lima, Arequipa y todas la franja costeña desde Ilo y Moquegua (Perú) hasta Iquique (Chile)-- han ocurrido también migraciones masivas desde la puna o altiplano, creando un nuevo estilo de aymara urbano que camufla su identidad ante los ajenos pero la mantiene en otro nivel de relaciones cotidianas (para el caso peruano consultar a Chirinos 1998 y Chirinos y Schwager 1997).

Hasta por lo menos el siglo XVII, de forma entreverada con el quechua, había aymara hablantes mucho más al norte hacia el Cusco y más allá, y seguían hablándose diversas variantes de aymara o lenguas emparentadas en áreas hoy totalmente quechuizadas del Perú central. Actualmente en la región de Yauyos, en las alturas del departamento de Lima, queda aún un millar de hablantes de una lengua emparentada, hoy llamada Jaqaru, es decir, 'palabra o lengua de la gente' (Belleza 1995, Ferrel 1996, Pozzi-Escot 1998). Pero éstos ya no mantienen contactos regulares con los aymaras del sur. Hay también grupos numerosos de aymaras emigrados a ciudades que quedan fuera de su territorio habitual, como Buenos Aires (Argentina) y sobre todo Arequipa y Lima, en la costa peruana.

Esta es la realidad linguística, que actualmente pesa bastante para marcar identidades diferenciadas. Pero en términos socio-culturales no es exacto medir la identidad étnica a partir de sólo el dato linguiístico: ni se identifican como aymaras todos los que hablan la lengua (aunque sí, la gran mayoría) ni pier- den esta identidad todos lo que ya no la hablan. En términos antropológicos tampoco tiene mucho sentido diferenciar entre una "cultura" quechua y otra aymara: parece más exacto y útil hablar de una cultura andina común que en unas partes se expresa en lengua quechua y en otras en lengua aymara (aparte de otra minoría uru chipaya). Aparte de la lengua, las variantes culturales internas dentro de este común denominador no se correlacionan con la lengua sino con las diversas ecologías y con la intensidad de sus relaciones con la formación social y económica dominante.

\section{Aymaras entre fronteras cambiantes}

No es tan claro que en las épocas precoloniales pudiera hablarse de una identidad común aymara ni de otra quechua. Más obvias eran las identidades a niveles inferiores, sean locales o más probablemente por adscripción a determinados linajes, ayllus o federaciones de éstos a niveles más o menos envolventes. El imperio (o "estado") inca, conocido como Tawantinsuyu o "las cuatro jurisdicciones unidas', habría sido el nivel máximo de asociación por conquista interna por parte de uno de los grupos, el inca. Pero ¿habrá llegado a generar un sentido de identidad común en todos los pueblos que lo componían?

Tampoco sabemos exactamente qué rol jugaba entonces cada lengua y sus múltiples variantes dialectales dentro de la identificación de estos grupos menores, aunque sí hay evidencias de que la distribución lingüística era entonces muy distinta de la actual y que se relacionaba más a zonas ecológicas --más aymara en las alturas y más quechua en los valles, aparte de otras lenguas-- y al acceso de los ayllus a diversos nichos ecológicos, a veces muy distantes, que a jurisdicciones geográficas contiguas (Bouysse Cassagne 1987: cap. 2).

La identificación de los aymaras como un grupo común, con su propio territorio siquiera lingüístico, fue en buena medida resultado de la nueva situación colonial, que "redujo" a los ayllus y comunidades en torno a nuevos pueblos, para fines fiscales, cortando progresivamente sus vínculos con sus avanzadas en otras ecologías (Saignes 1978), y que fomentó determinadas "lenguas generales" o francas para facilitar la evangelización. Se consolidaron así dos vastos territorios lingúísticos, uno quechua y otro aymara. Al parecer, esta reconversión 
de la identidad en torno a una lengua y territorio común se consumó sobre todo durante el siglo XVIII (Albó 1987 y 1988).

Por entonces todo este territorio aymara formaba parte del mismo virreinato del Perú (o de Lima), que cubría también la mayor parte del territorio quechua, sujeto a un proceso semejante. Dentro de él la mayor parte del territorio aymara quedaba unitariamente dentro de la audiencia de Charcas, que entonces cubría también la parte aymara hoy correspondiente al Perú, hasta la serranía llamada precisamente La Raya --por ser la frontera jurídica--, parte de la Cordillera del Vilcanota que separa la cuenca lacustre del Titicaca de las aguas que fluyen ya hacia el Amazonas.

Otra parte de la población aymara está en la franja de Arica y Tarapacá, que hoy constituye la I Región, en el extremo norte de Chile. En la época colonial, después de algunos intentos iniciales por anexarla también a Charcas (como ocurría ya con Atacama, más al sur), esta franja pasó a depender directamente del Virrey de Lima, a través del gobernador delegado de Arequipa. Pero en la práctica su situación era algo anómala. Jurídicamente dependía de Lima y Arequipa pero al mismo tiempo, por su mayor cercanía, seguía siendo el "puerto de Potosí" y la puerta natural de Charcas, por donde circulaban manufacturas y minerales entre el altiplano y la Costa (Abecia 1979: I, 109-113, Van Kessel 1992: 130).

Gracias a estudiosos como el aymara Roberto Choque, conocemos en detalle la historia de diversos caciques aymaras a lo largo de todo ese período colonial y en ellas sobresale su gran movilidad y la amplitud de sus relaciones a lo largo y ancho de todo el territorio aymara, sin que por entonces significaran mucho las actuales fronteras estatales. Por ejemplo, los célebres caciques Fernández Guarachi, de Jesús de Machaqa (hoy, dentro de Bolivia) tenían sus redes comerciales en lugares tan distantes que iban desde la costa de Moquegua y Cusco (hoy Perú) hasta Potosí (hoy Bolivia) y el actual norte de Chile. Estas se apoyaban a su vez en políticas matrimoniales y redes de parentesco que los vinculaban con los descendientes de los incas y otros caciques a lo largo y ancho de su área de influencia (Choque $2001 \mathrm{Ms}$ ).

En 1776 se creó el nuevo virreinato de La Plata (o de Buenos Aires), como fruto del crecimiento del comercio por el Atlántico, y de él pasó a depender toda la audiencia de Charcas. Pero este paso no supuso aún un corte en la unidad interna aymara dentro de dicha audiencia, pues su límite noroeste seguía siendo La Raya, ya en territorio de habla quechua.

Pocos años después de este cambio, en 1780-1782 ocurrió el levantamiento general de los varios Tupaq? Amaru, desde el Cusco (virreinato de Lima) y de los hermanos Katari y de Julián Apasa o Tupaq Katari, en la audiencia de Charcas (recién pasada al virreinato de Buenos Aires). Por entonces, los primeros eran casi exclusivamente de habla quechua y entre los segundos predominaba el aymara, con áreas quechuas en zonas de valles. Por su diverso origen geográfico y linguíístico, hubo algunas tensiones entre líderes de ambos bandos, cuando llegaron a confluir en el célebre cerco de La Paz (1781). Pero lo que más llama la atención es la unidad de este movimiento sin tomar en cuenta ni las diferencias lingüísticas ni las barreras creadas por las jurisdicciones virreinales. Estas últimas aparecen sobre todo en el hecho de que el levantamiento es sofocado en Charcas con un ejército enviado desde el sur y, en el Cusco, con otro enviado desde el norte. Han sido más bien los historiadores posteriores, unos adscritos al Perú y otros a Bolivia, los que han tenido la tendencia a analizar por separado, influenciados por las fronteras posteriores, lo que en realidad constituyeron en su tiempo sólo diversas fases de un único movimiento ${ }^{3}$.

Casi inmediatamente, en 1784, se segregó de La Paz la nueva intendencia ${ }^{4}$ de Puno, con un límite que cruzaba el lago Titicaca de noreste a sur, hasta el inicio del río Desaguadero. Inicialmente ambas seguían dentro de la Audiencia de Charcas. Pero en 1796 la nueva intendencia de Puno volvió a formar parte de su anterior virreinato de Lima, aunque en el orden eclesiástico tres de sus provincias siguieron siendo parte del obispado de La Paz, pasando al del Cuzco sólo con la Independencia (Abecia 1979: I, 170-173; Barnadas 1989: 77-79).

2 Escrito también Tupa, Tupac y Tupaj. En cada caso usaremos la escritura preferida por la organización citada.

3 O'Phelan (1995) es una de las principales excepciones a esta tendencia a diseccionar por países. Hidalgo (1986) muestra cómo en la región periférica que hoy es de Chile influyeron entonces tanto los Amaru como los Katari.

4 Las intendencias eran una nueva categoría jurisdiccional creada como parte de las reformas borbónicas que tanto habian influido en la rebelión indígena de 1780. 
Este último cambio fue la base para que, al crearse los nuevos estados independientes del Perú (1821) y Bolivia (1825), se adoptara esta última línea fronteriza y no la histórica de La Raya, con lo que la unidad aymara sufrió un quiebre definitivo entre dos estados soberanos. El Perú se quedó con todo lo que quedaba al norte y oeste del lago Titicaca, que pasó a formar parte del nuevo departamento de Puno, y con la parte aymara de Arica y Tarapacá, que nunca perteneció a Charcas y que ahora pasó a formar parte del departamento de Arequipa (y posteriormente, del de Moquegua, escindido del primero), y también. El resto, donde habitaba la mayor parte de la población aymara, correspondió a Bolivia.

Esta frontera entre Perú y Bolivia necesitó varias décadas para consolidarse. Andrés de Santa Cruz, nacido a orillas del lago Titicaca en Huarina (hoy Bolivia), hijo de padre español, vinculado a la aristocracia cusqueña, y de madre aymara, hizo todavía un intento de federar a los dos países. En 1826-27 fue presidente del Perú y desde 1829 lo fue de Bolivia, aunque siguió interviniendo activamente en la política peruana, de modo que en 1836, después de una intervención militar, llegó a formar una efímera federación peruano-boliviana. Pero este esfuerzo acabó a principios de 1839 al ser derrocado de ambos países, con intervención militar chilena. En 1841, el peruano Agustín Gamarra intentó un movimiento anexionista de sentido contrario pero fue derrotado en la batalla de Ingavi (Klein 1982). Aunque todas estas movidas se realizaban prescindiendo de la población aymara, directamente afectada, si se hubiera consolidado alguna forma de federación bi-estatal, la historia aymara habría sido sin duda distinta.

Décadas después, la Guerra del Pacífico (1879-82), para el control del salitre y otros recursos minerales, fue ganada por Chile, que se anexionó nuevos territorios de los perdedores, habitados en parte por aymaras. En concreto, la provincia peruana de Moquegua quedó partida: de Tacna hacia el norte, en manos del Perú; y, de Arica hacia el sur, en manos de Chile. Más al sur, en área ya no aymara, Chile se quedó con todo el departamento de Atacama, hasta entonces boliviano pero que ya estaba ocupado desde antes por población y capitales chilenos. Con ello cerró el acceso soberano de Bolivia al mar. Chile ofreció como compensación la construcción de un ferrocarril, oferta que fue vista con buenos ojos por los mineros bolivianos y que --como vere- mos-- tendrá también sus consecuencias para el pueblo aymara.

En la delimitación de estas fronteras, por lo general, se respetaron los linderos internos de ayllus y comunidades, pero no faltaron casos en que una misma unidad local quedó partida entre Bolivia y Perú o entre Bolivia y Chile. Más adelante analizaremos alguno de estos casos.

Sin querer desconocer el persistente peso de una larga historia previa con una lengua y cultura común, no debe tampoco subvalorarse el impacto más reciente de esta fragmentación del mundo aymara en tres países distintos, con sus pugnas entre sí y con desarrollos internos diferenciados. Aunque los aymaras de los tres países se sienten hermanos cercanos, por el hecho de entenderse en la misma lengua, cada grupo se siente también muy involucrado con los avatares políticos, económicos y culturales del país y estado del que, por los avatares de la historia, han pasado a formar parte.

En las próximas páginas iremos viendo como se va desarrollando a lo largo de los años, de manera entrelazada, esta doble influencia: una más centrípeta pan aymara, como resultado de la larga historia común; y otra más centrífuga, como resultado de la inserción de cada sector en la historia diferenciada de su diversa matriz estatal.

\section{Los aymaras bolivianos}

$\mathrm{Al}$ ser actualmente los más numerosos, por mucho, y al estar más cercanos a La Paz, sede del gobierno, ubicada en el corazón de su territorio, son sin duda los que juegan un rol hegemónico dentro de todo el mundo aymara, al menos en los períodos aquí cubiertos. Por eso partimos de ellos, como referente tipo, para desde ahí ir haciendo comparaciones con lo que ha ocurrido en los que quedaron escindidos en otras realidades políticas.

Pese a la fuerte discriminación de que han sido objeto, a lo largo del período republicano, los aymaras han ido jugando un rol significativo dentro de la historia boliviana, aunque muy diferenciado en su impacto y puntos de énfasis, de acuerdo a cada momento y coyuntura. Distinguiremos tres grandes períodos históricos: 
Primer período

Es el de la resistencia militante al expolio y se extiende desde la segunda mitad del siglo XIX hasta el final de la guerra del Chaco (1932-1935). Se inicia con la recuperación de la minería de la plata, que dio al Estado una nueva fuente de recursos, por lo que se fue perdiendo el interés en la tributación indígena comunal, que antes era su principal sustento. Con ello perdía también importancia el mantenimiento de esas tierras comunales y se multiplicaron los intentos de los terratenientes, amparados en gobiernos favorables, para irles arrebatando sus tierras. En toda esta época de menos de un siglo se apoderaron de tanta tierra comunal como la que se había apropiado el régimen colonial en tres siglos y medio. No fue una ocupación tranquila sino que estuvo marcada por cientos de levantamientos y sublevaciones indígenas contra esta usurpación, los cuales con frecuencia desembocaron en brutales masacres.

Este proceso se inició hacia los años 1860 , se cortó temporalmente durante la participación boliviana en la guerra del Pacífico en 1879 y después prosiguió casi sin interrupción hasta la guerra del Chaco, durante la cual el traslado del ejército al campo de batalla generó una mayor oleada de levantamientos. Aunque afectaron también a otras regiones de habla quechua, estos movimientos se dejaron sentir sobre todo en comunidades y ayllus aymaras, cuya ubicación en áreas frígidas de altura había fomentado menos la ambición de los españoles durante el anterior período colonial.

Los expoliadores tenían intereses materiales muy específicos. En primer lugar, estaba el interés minero primero por la plata y, desde fines del siglo XIX, por el estaño. Los principales yacimientos mineralógicos estaban ubicados mayormente en las punas y serranías andinas, en tierras de ayllus que se veían invadidos por las empresas. Desde la derrota de Bolivia frente a Chile en la guerra del Pacífico se añadió como nuevo factor la construcción de ferrocarriles que unían la costa chilena con los principales centros mineros y urbanos, en parte como compensación del vencedor. Aunque inicialmente destinados a exportar minerales, el avance de los rieles aumentó la ambición de muchos expoliadores por el nuevo valor comercial que se suponía iba a adquirir la tierra del contorno.
Las clases dirigentes apelaban además a la nueva ideología que combinaba la vieja lógica de los estamentos étnicos coloniales, que subordinaban a los indígenas al español y sus descendientes, con las nuevas ideas del liberalismo, que asociaban la democracia liberal con el acceso individual a la propiedad privada, y las nuevas corrientes darwinistas, que subrayaban con argumentos pseudo científicos la superioridad de la raza blanca.

Muchos de estos levantamientos desembocaron en masacres por parte del ejército, sin que haya una diferencia significativa de conducta, según se trate de gobiernos conservadores, liberales o republicanos, por citar sólo los principales partidos de ese período. Otra constante, es que cualquiera de esos partidos era más sensible a la causa indígena mientras se encontraba en la oposición y necesitaba el apoyo de otros sectores. Buscaban su apoyo aduciendo su solidaridad frente a los despojos que sufrían por parte de quienes detentaban el poder pero, una vez establecidos en él, los nuevos gobernantes caían en lo mismo que antes habían criticado, porque desde el punto de vista estructural eran parte de la misma oligarquía terrateniente y minera (Albó y Barnadas 1995: 150-172).

Desde la perspectiva comunal, se conformaron en este período amplias redes que aglutinaron a diversos líderes mayormente aymaras desde La Paz hasta Potosí, dentro de lo que actualmente se conoce como el "movimiento cacical", iniciado ya en las últimas décadas del siglo XIX y continuado, con diversos acentos y altibajos, hasta plena guerra del Chaco. Sus dos temas centrales fueron la defensa y recuperación de tierras y el acceso a la educación. Un rasgo simbólico fundamental es que, a partir de 1914, estos dirigentes adoptaron el título de "caciques" (sin ningún sentido peyorativo), en continuidad con el sistema existente durante la Colonia, como parte de su intento de restaurar un sistema de gobierno autónomo aymara (Mamani 1991: cap. 2, Rivera 1991, Ticona y Albó 1997: 89-139). Ya unos años antes, en el marco de la guerra federal o "de capitales" de 1899 entre los criollos de Sucre y La Paz, se desarrolló la gran rebelión indígena dirigida por los aymaras Zárate Willka y Juan Lero y este último constituyó en Peñas, Oruro, un breve "gobierno indígena", del que llegó a titularse "presidente" (Condarco 1982: 376-378). Treinta años después, en 1930 y en pleno movimiento cacical, Eduardo Leandro Nina Quispe fundó en La Paz y fue "pre- 
sidente" de la "Sociedad República del Qullasuyu", nombres que le valieron la cárcel por "usurpación de funciones del Estado" (Choque 1985, Mamani 1991).

\section{Segundo período}

Lo podemos caracterizar como la era de la reforma agraria y los sindicatos campesinos. Hubo un período inicial de transición (1936-51), en que la clase política volvió a repensar el país, abatido por su nueva derrota en el Chaco. Pero la nueva situación se consolidó sobre todo a partir de la revolución del 9 de abril de 1952, extendiéndose hasta fines de los años 60 .

Hasta 1964 se caracteriza por una relación mucho más estrecha entre estos aymaras y quechuas y el MNR (Movimiento Nacionalista Revolucionario), el partido gobernante, que les devolvió tierras de haciendas arrebatadas en períodos anteriores, generalizó las escuelas en el campo y los organizó en "sindicatos campesinos", con cierta participación política subordinada y con una organización de alcance nacional: la Confederación Nacional Campesina. Todo este tiempo supone una mayor identificación entre estos sectores sociales indígenas y el nuevo "estado nacional", que por fin les da cierto reconocimiento.

El principal efecto económico de estas medidas fue la liberación del régimen de hacienda allí donde éstas existían, incluyendo buena parte del mundo aymara al norte del río Desaguadero. Los ex peones se transformaron en propietarios de las parcelas con cuyo usufructo eran antes compensados a cambio de tres a cuatro días semanales de trabajo gratuito para la hacienda. Además duplicaron el tiempo de trabajo que podían dedicar a ellas. Mejoraron en lo inmediato su propia dieta, mientras que las ciudades notaron un significativo bajón en el flujo de productos agrícolas. Uno de los efectos quizás no previstos de la Reforma fue entonces el surgimiento de numerosas ferias y hasta nuevos pueblos rurales que ya no estaban en manos de mestizos sino de comunarios. En ellas se redistribuían productos agropecuarios de las diversas regiones pero también otros artículos manufacturados antes inasequibles, desde azúcar hasta bicicletas, que convertían a los campesinos también en pequeños consumidores.

Al nivel político ese campesinado agradecido se convirtió en uno de los principales soportes sociales del gobierno, asegurando una votación masiva por el MNR en las diversas elecciones que entonces se dieron y también un apoyo militante de sus "regimientos populares", armados con viejas armas de la guerra del Chaco, cuando en las ciudades ocurrían intentos de golpe y otros disturbios.

El MNR cayó del poder a fines de 1964 pero el siguiente gobierno militar, del carismático general Barrientos (1964-1969), siguió una política populista semejante, a través del llamado "Pacto Militar Campesino". Aunque su máxima popularidad se dio en Cochabamba, en el área quechua, los aymaras participaron de esa misma corriente. Es significativo, por ejemplo, que en 1967 los campesinos apoyaron unánimemente a su general cuando el Che y su puñado de cubanos y bolivianos iniciaron su aventura guerrillera en el Chaco guaraní, lo que entonces fue visto sobre todo como una incursión extranjera, a diferencia de lo que percibían, por ejemplo, los mineros y otros sectores urbanos.

\section{Tercer período}

Es el de la emergencia aymara. Las tendencias "campesinistas" del período anterior, si bien eran parte del deseo de fortalecer la identidad nacional boliviana, no implicaban necesariamente barrer del todo la rica cultura aymara, tan presente en celebraciones, festivales e incluso en programas de radios. Pero además desde los años 60 en la ciudad de La Paz y algunos lugares del altiplano ya se venía preparando de forma subterránea un movimiento más orgánico de reivindicación étnica. Este se consolida hacia 1968-69 cuando, tras la muerte del general Barrientos en un accidente aéreo, los gobiernos militares que le sucedieron ya no supieron desarrollar el mismo carisma de acercamiento al sector campesino. A medida que se iba despintando la ilusión de progreso campesino creado por el MNR, fue surgiendo una nueva corriente que se llamó "katarista" en recuerdo del héroe colonial Tupaq Katari, que en 1781 había puesto en jaque al régimen colonial español en la ciudad de La Paz.

El katarismo ha sido un fenómeno sobre todo aymara, caracterizado ante todo por el redescubrimiento de su identidad, tan diluida en el período anterior. En sus orígenes estuvo liderado sobre todo por jóvenes que estaban estudiando en la ciudad de La Paz --en parte como fruto de los 
cambios introducidos por el MNR-- y que supieron catalizar las frustraciones que sentían muchos campesinos al no lograr el progreso material con que tanto habían soñado al pasar de "indios" despreciados a "campesinos" participantes. Algunos de ellos lo expresaron explícitamente al decir que se les había reducido a una "clase social", perdiendo a cambio su condición de "pueblo aymara".

Los kataristas saltaron a la palestra mediante sus propios programas en una radio comercial, en torno a los que se formó el "Centro Cultural Tupaj Katari" con fondos propios de la gente y después, con estos mismos fondos, en otra en que compraron acciones. Con esa base, se lanzaron también a conseguir un lugar en la Confederación Nacional Campesina y de hecho en Julio de 1971, en los últimos días de gobierno del general Torres, llegaron a escalar los cargos máximos de esta organización. Pero a lo pocos días este movimiento en ascenso fue silenciado por el golpe militar del general Banzer que persiguió a esos dirigentes kataristas poco afines, clausuró sus programas radiofónicos y congeló sus bienes.

Durante esos siete años de dictadura (1971-78) el Pacto Militar Campesino fue entrando en crisis por su estilo autoritario, que en 1974 incluyó una masacre a quechuas en Cochabamba. Poco a poco el katarismo reapareció, de forma todavía clandestina, bajo el lema de acabar con ese pacto. En 1978, por presiones tanto internas como del gobierno norteamericano de Jimmy Carter, se inició un agitado proceso de democratización con una seguidilla de elecciones, golpes y contragolpes, hasta que en 1982 se inició un período democrático que ya ha pasado la prueba de cinco gobiernos constitucionales. ${ }^{5}$ Precisamente durante esa transición, en 1979, el katarismo retomó el liderazgo de la organización campesina nacional unitaria que, independiente ya del viejo pacto con los militares, adoptó entonces la nueva sigla CSUTCB (Confederación Sindical Unica de Trabajadores Campesinos de Bolivia). Este nombre "sindical" refleja la larga tradición iniciada por el MNR en 1952 y fue un compromiso con otros sectores del país, que no vibraban tanto por lo étnico. Pero no debe hacernos pensar que esta perspectiva se había perdido en el sector aymara; de hecho la Federación Departamental de La Paz mantuvo

5 Paradójicamente, el más reciente, actualmente en ejercicio, está en manos del ex dictador Banzer. --y mantiene hasta hoy-- en su título el nombre de Tupaj Katari.

El momento de mayor esplendor del katarismo fue entre 1977 y 1984, en que participó militantemente en el derrocamiento de los regímenes militares, el retorno a la democracia y logró un amplio apoyo en el campesinado aymara y quechua. Además de la figura legendaria de Tupaj Katari, se utilizaron masivamente nuevos signos identificadores, como la wiphala, o bandera aymara, los ponchos y pututus (cuernos de asamblea y guerra), entre otros y se inició un conjunto de demandas de tipo étnico y social, como la educación intercultural bilingüe, el reconocimiento y autonomía parcial de sus autoridades tradicionales y forma de gobierno, radios propias, mejores precios para sus productos, acceso a créditos, etc.

Ya en 1978, inmediatamente después que volvió la democracia, formó también sus pequeños partidos políticos que terciaron en las diversas elecciones con muy poco apoyo logístico, débil organización interna y bajos resultados, pero que tuvieron la virtud de introducir su temática, entonces muy novedosa, en la esfera pública. En ellos se desarrollaron enseguida dos grandes corrientes:

(a) La primera, en que sobresalía el MRTK (Movimiento Revolucionario Tupaj Katari), tuvo desde un principio un enfoque más social y abierto al dialogo con otros sectores sindicales y políticos de izquierda, y también una mayor convocatoria en el sector rural, por sus estrechos vínculos con la CSUTCB, surgida de su seno. Es central en ella la importancia dada de la dimensión étnica (ignorada por varios de sus interlocutores), pero no lo hace a expensas de la dimensión clasista, que acepta también como algo fundamental, porque se vive a diario en el campo (p. e., en todo el sistema de precios y en el acceso a la tierra, crédito y servicios básicos). En aquellos años se escuchaba con frecuencia que había que mirar la realidad "con los dos ojos" y avanzar "con los dos pies": como etnias o naciones oprimidas, junto con los demás pueblos indígenas; y como campesinos, junto con los demás sectores de la clase explotada.

(b) La segunda, Ilamada también "indianista" y en la que sobresalía entonces el MITKA (Movimiento Indio Tupaj Katari), se ha centrado más en una ideología basada en la oposición histórica entre los "in- 
dios", originarios de este continente, y los españoles y sus descendientes, los $q^{\text {}}{ }^{\text {aras }} .{ }^{6}$ Rechazan en cambio el enfoque de clase y el marxismo, como ideas "foráneas", y denuncian el carácter igualmente q'ara de los políticos convencionales, sean de derecha o de izquierda. Siempre han tenido una base local más reducida, mayormente urbana, pero una mayor vinculación internacional con los movimientos indios de otros países. Justifican su énfasis en lo "indio" apelando a una frase atribuida a Domitila Quispe C., de Azángaro (Perú 1922): "Indio fue el nombre con que nos sometieron, Indio será el nombre con el que nos liberaremos!”.

Al principio existió una mayor tensión entre las dos corrientes, sobre todo en torno al presunto "racismo" de los segundos. Pero con los años gracias al énfasis común en los temas del "neocolonialismo" y de la identidad étnica, como elementos fundamentales para interpretar la realidad e incidir sobre ella, se ha ido logrando una mayor flexibilidad y acercamiento entre ambas corrientes. Puede ser un símbolo de esta mayor convergencia el consenso que se ha ido creando en torno a una autoidentificación como miembros de una "nación aymara", que forma parte de los numerosos pueblos o naciones "originarias" del continente. El problema irresuelto han sido más bien las constantes fragmentaciones en ambas corrientes, por cuestiones de liderazgo, finanzas y alianzas políticas. En algún momento llegó a haber más de diez partidos kataristas, todos ellos minúsculos. ${ }^{8}$

En este resurgimiento, el katarismo --sobre todo en su primera vertiente-- contó además con el apoyo de ciertos sectores de las iglesias católica y metodista, el de varias ONGs más sensibles a esta temática y, más adelante, el de unos pocos partidos minoritarios de izquierda; otros partidos de izquier$\mathrm{da}$, en cambio, seguían aferrados inicialmente a su

6 Nombre genérico quechua y aymara para los blancos y mestizos. Literalmente, significa "desnudo, pelado", es decir el que carece de algo fundamental. El término deja entrever cierta connotación de "salvaje" (el que no cumple ciertas normas culturales básicas). Los aymaras actuales le dan también cierto sentido clasista: el que no tiene nada propio, porque lo que tiene lo ha expoliado sin trabajo; un aymara puede hacerse q'ara, si se aliena de su pueblo y se comporta como blanco.

7 Término que muchos rechazan sea por sus connotaciones despectivas o por derivarse del error geográfico de Colón, que inicialmente había pretendido llegar a la India.

8 La primera rama ha sido la más analizada (ver Hurtado 1986 y Albó 1985, 1993, entre otros). Para la segunda, ver Pacheco (1992). esquema clasista y veían todo este movimiento como algo peligroso. Logró un buen efecto multiplicador a través de sus programas en aymara difundidos en radios de estas instituciones de apoyo, sobre todo Radio San Gabriel ${ }^{9}$ de la red ERBOL (Educación Radiofónica de Bolivia).

De forma complementaria, ya desde los años' 70 han ido surgiendo, sobre todo en la ciudad de La Paz, numerosas instituciones total o parcialmente en manos de aymaras urbanos, que cubren una inmensa gama de temáticas relativas a esta nación.

La lista incluye numerosos "centros de acción" para beneficio de sus comunidades de origen, proyectos de apoyo al campo, conjuntos folklóricos, centros de investigación y reflexión histórica, de salud y medicina andina, de promoción lingüística, pequeñas publicaciones, radios o centros de producción de programas radiofónicos, grupos estudiantiles, de acción política, etc. (Sandóval, Albó y Greaves 1987). Unos son más espontáneos, otros son más institucionalizados, sobre todo si cuentan con apoyo financiero externo. Pero el conjunto muestra la vitalidad que sigue teniendo la problemática aymara en el ámbito urbano.

Desde la perspectiva aymara hay cierta continuidad de enfoque a lo largo de todo este período, en medio de indudables altibajos y de adaptaciones a las nuevas coyunturas políticas y económicas. En la última década el katarismo, como movimiento organizado, se ha ido fragmentando y diluyendo pero --paradójicamente-- sus ideas centrales han ido penetrando más bien en el conjunto de la sociedad civil y política.

Esta mayor difusión de las nuevas ideas no se debe sólo al tesón de los pioneros kataristas. En los años ' 80 se le añadió un fuerte movimiento de los grupos

\footnotetext{
9 Radio San Gabriel, de la Iglesia Católica, fue inicialmente creada por los misioneros Maryknoll en la localidad altiplánica de Peñas ya en los años' 50 para fines catequéticos y de extensión de la educación escolar. Pero en los años' 70 se trasladó a La Paz, aumentó notablemente su potencia y diversificó mucho más su programación, fomentando en ella la participación activa de la audiencia, aunque sin abandonar nunca su carácter institucional. Se autodenomina "la voz del pueblo aymara" y es efectivamente la radio más sintonizada en todo el mundo aymara con un alcance que va más allá de las fronteras bolivianas. En los años' 90 ha dado pasos para complementarse con un canal de TV aymara, pero hasta el momento de escribir estas líneas aún no ha podido implementarse.
} 
indígenas minoritarios de la selva y empezaron a influir también la crisis mundial de las ideologías izquierdistas tradicionales, tras el derrumbe de los regímenes comunistas del este europeo, con lo que el viejo énfasis clasista cedió ante el pluriétnico. Fueron también favorables para el cambio de paradigma las nuevas corrientes ecologistas, feministas, postmodernistas, etc. que más fácilmente entran en sintonía con la causa indígena, dentro de un enfoque que respeta más el pluralismo y la alteridad.

Señalemos los tres hitos simbólicos más significativos dentro de este cambio. El primero fue el surgimiento del partido CONDEPA (Conciencia de Patria), del folklorista Carlos Palenque, más conocido como "el compadre", que en 1989 llevó al parlamento a la primera cholita de pollera. El segundo, fueron las masivas movilizaciones a todas las ciudades de la región andina, en torno al 12 de octubre de 1992 (conmemoración de la llegada Colón a América), que todos los indígenas del continente reinterpretaron militantemente como "500 años de resistencia". Los aymaras jugaron en ello un importante papel, en compañía de otros muchos pueblos indígenas, dentro y fuera de Bolivia. Un tercer hito fue el nombramiento de un aymara, el antiguo katarista Víctor Hugo Cárdenas, como vicepresidente del país. Anteriormente había participado activamente tanto en la CSUTCB como en uno de los varios partidos políticos kataristas, que nunca lograron más de uno o dos diputados. Pero en 1993 se alió con un presidente neoliberal y empresario quien, tras un sondeo de marketing político mediante grupos focales, decidió presentarlo como vicepresidente y juntos ganaron. Aunque su gestión no estuvo exenta de controversias, por esa alianza difícil de digerir, hay que reconocer que su alta investidura, con la permanente presencia de su esposa también de pollera, ha marcado un antes y un después en la historia reciente del pueblo aymara e incluso de los pueblos indígenas del Continente.

\section{Más allá de las fronteras}

Pero los intercambios más significativos, son los que se han creado en el tercer período. Podemos distinguir tres flujos. El primero, es un antecedente de iniciativa más institucional, apoyado por algunos sectores de iglesia desde fines de los años' 60 , sobre todo después del Concilio Vaticano II (ver la próxima sección). Los intercambios más indirectos surgidos del auge de radios en aymara tienen tam- bién cierta relación con este primer flujo, dado el carácter institucional de sus principales emisoras.

El segundo flujo, más de base, es el más significativo para nuestro tema y tiene que ver con la emergencia del katarismo en Bolivia. Este movimiento se centró inicialmente en este país y su expansión natural fue hacia otras regiones dentro de Bolivia. Pero tuvo un evidente efecto en los otros dos países, primero a través de las radios en aymara y, con el tiempo, también a través de contactos más personales sea sólo entre líderes aymaras o en eventos de carácter más amplio, por ejemplo, en torno a la temática indigenista-indianista o a problemas más específicos como la producción de hoja de coca. Más adelante iremos precisando el alcance de estos influjos en cada país y en el conjunto del territorio aymara.

El tercer flujo, parte de nuevos enfoques educativos, con énfasis en el uso de la lengua materna aymara (quechua, etc.). Tiene una mayor presencia estatal, incluida la cooperación de diversas agencias públicas internacionales. Por el carácter pionero que en ello tuvo el Perú, lo desarrollaremos también en el siguiente capítulo.

\section{Los aymaras peruanos}

El núcleo central de la región aymara peruana, que colinda con Bolivia por el norte y occidente del lago Titicaca, es ecológicamente muy semejante a la boliviana, salvo por el hecho de que, además del altiplano y una región de valles y yungas hacia la selva oriental, cuenta también con valles costeros y ciudades costeñas, receptoras de muchos inmigrantes. Pero social y políticamente hay una gran diferencia a un lado y otro de la frontera: los aymaras bolivianos están muy cerca de La Paz, la capital del país, en cuya área metropolitana más de la mitad sabe aymara. En cambio los aymaras peruanos quedan en el último rincón de su país, a gran distancia de Lima, capital del país y centro de toda su actividad económica. Esta situación explica también las tempranas emigraciones hacia toda la costa, particularmente a sus principales centros urbanos, desde Tacna hasta Lima, que es el caso más estudiado (Altamirano 1984, 1988).

Para nuestro análisis comparativo, es útil retomar los tres momentos señalados en la sección precedente, que nos brindan un marco cronológico com- 
parable..$^{10}$

\section{Primer período}

En el Perú hay también hay un primer período largo de resistencia, que se inicia más temprano que en Bolivia y se prolonga hasta fines de los años' 60 , cuando llegó por fin la reforma agraria del general Velasco Alvarado.

También allí la burguesía, sobre todo de Arequipa, desarrolló un nuevo interés por las tierras de altura, pero en ese país, mejor comunicado con el resto del mundo, se debía sobre todo a la importancia económica que había adquirido la exportación de lana de alpaca a las manufacturas inglesas. Entre 1870 y 1874 construyó también un ferrocarril que conectaba Arequipa y la costa del Pacífico con el altiplano, en este caso para exportar la lana, provocando de paso un interés adicional en tierras comunales." Como consecuencia de todo este auge lanero, tanto en el altiplano aymara como en otras partes de la sierra peruana, en el siglo XIX se produjo una avalancha de expoliaciones de tierras comunales, con la subsiguiente secuela de sublevaciones y masacres, paralelas a las que ocurrían en Bolivia como analiza Gow (1981). La situación fronteriza de esos aymaras fomentó además una mayor presencia del ejército peruano para sofocarlas. Como señala el estudioso aymara puneño Domingo Llanque ${ }^{12}$, en cada pueblo fronterizo en que estalló una sublevación, sofocada con sangre, se levantó un cuartel estable. Es evidente que la situación fronteriza era entonces aprovechada como una posible válvula de escape. Cuenta otro testimonio: "El ejército estaba viniendo... Nosotros, pensando que iba a llevar presos a toda la población, escapamos hacia Bolivia" (en Sandóval y Albó 1978: 12).

10 En realidad, esta periodificación tiene también un paraleio temático en otros varios países andinos, aunque con ciertos desfases cronológicos entre ellos. como se explica en mayor detalle en Albó (1999), donde el lector encontrará también bibliografía adicional de apoyo.

11 Se construyó también un ramal que, con transbordo a lo largo del lago Titicaca, llegaba desde Puno hasta La Paz, Bolivia, en este caso para la exportación de minerales.

12 Comunicación personal.

13 Es muy revelador que el indianista aymara boliviano Kara [o Germán] Chukiwanka (1989) consideró importante escribir un folleto de divulgación sobre la historia de este luchador que era de origen criollo, y se estableció en una región quechua del Perú.
Hay incluso el caso notable del mayor de caballería Teodomiro Gutiérrez, que en 1912 fue comisionado a Puno para recoger "las quejas de la indiada". Quedó tan impresionado y se sintió tan solidario, que él mismo empezó cambió su nombre por el de Rumi Maki ("mano de piedra", en quechua, se parapetó en Samán, cerca de la frontera lingüística quechua-aymara, proclamó el "Gobierno Socialista del Tawantinsuyu" y armó un ejército que resistió hasta 1915. Aunque este movimiento no fue propiamente aymara, toca muy de cerca de este pueblo y representa uno de los primeros y mayores cuestionamientos de los estados criollos en territorio andino. ${ }^{13}$

Pero es también evidente que en el lado occidental el referente central era ya el estado peruano y, a pesar de la distancia a su capital Lima, mientras que en el lado oriental el referente era el estado boliviano. Un caso paradigmático es la sublevación de unas comunidades cercanas al pueblo mestizo de Huancané, al norte del lago en 1923, que desembocó en la creación de un nuevo pueblo y capital, en competencia con el centro mestizo, en base a planos traídos desde la lejana capital nacional y al que significativamente se dio el nombre de Huancho Lima (Llanque 1981; Albó, 1999).

\section{Segundo período}

La revolución y reforma agraria boliviana del MNR, que hemos caracterizado allí como segundo período, tenía cierto correlato en algunos partidos peruanos, sobre todo en el APRA. Pero en el momento en que se gestó y empezó a realizarse este cambio en Bolivia, el Perú estaba en una coyuntura política y económica muy distinta, caracterizada por el desarrollo del capitalismo agrario costeño, que atraía a grandes masas de inmigrantes serranos, incluidos los aymaras de la puna. En toda esta época los aymaras bolivianos miraban un poco por encima del hombro a sus hermanos peruanos, precisamente por sentirse más adelantados con su reforma agraria, sus sindicatos y sus escuelas.

Un proceso comparable al boliviano pero mucho más débil empezó a darse en el Perú recién a partir de 1956. Inicialmente allí prevaleció más bien una situación crónicamente conflictiva de tomas masivas de tierras, estimuladas sin duda por el ejemplo boliviano, pero no precisamente en el área aymara colindante: el frente más cercano a ésta era el de La 
Convención en la selva del departamento del Cusco. El fundador del APRA, Raúl Haya de la Torre, ganó las elecciones de 1962 pero un golpe militar le impidió llegar al poder. En 1963 el nuevo presidente Belaúnde se sintió obligado a incorporar el tema de la reforma agraria en su programa de gobierno pero persistían las tomas y su ley de reforma tenía como permanente contrapunto la persecución a quienes las dirigían. En 1964 la situación se complicó con tres frentes guerrilleros (de nuevo, el más cercano al área aymara estaba en La Convención, Cusco) liderados por partidos urbanos de izquierda y que al fin fueron derrotados por el mismo Belaúnde, cuyos planes de reforma iban quedando aguados o postergados.

Hubo que esperar hasta 1968, en que el golpe y régimen militar de Velasco Alvarado impuso desde arriba una reforma, inspirada en el colectivismo yugoslavo, que transformaba haciendas en grandes empresas semiestatales llamadas SAIS --varias de ellas con decenas de miles de hectáreas-- o en cooperativas menores, llamadas CAPS. La región aymara entró también en este proceso, sobre todo con varios SAIS de ganado lanero. Pero ni allí ni en otras regiones andinas llegaron a satisfacer a las comunidades de base, pues la reforma se volcó sobre todo en esas grandes unidades, poco practicables y menos participativas. Las comunidades, propiamente dichas, que agrupaban al $50 \%$ de la población rural, se beneficiaron apenas con el $10 \%$ de las tierras redistribuidas. El resultado fue la polarización de todo el campesinado en una doble rama sindical campesina: la CNA (Confederación Nacional Agraria) oficialista y la CCP (Confederación Campesina Peruana) opositora.

Como en Bolivia, una y otra insistían más en lo "campesino" y clasista que en las identidades culturales y étnicas, enfoque que entonces se consideraba anticuado y que debía superarse. Velasco Alvarado tuvo cierta apertura a esta dimensión, por ejemplo, al oficializar la lengua quechua (algo que el MNR boliviano nunca consideró), apoyar un periódico y fomentar festivales populares de contenido andino. Reivindicó la figura del líder anticolonial quechua Tupac Amaru, pero para acomodarla a su proceso y discurso nacionalista reformista militar (Morin 1983: 212-239). Dentro de todo ello, lo específicamente aymara tuvo poco eco en el nivel oficial.
En cuanto a las relaciones entre aymaras a ambos lados de la frontera, persistían las relaciones de tipo tradicional, tomando siempre ventaja de las nuevas coyunturas que ofrecía la situación de cada país, pero sin una significativa influencia del nuevo proceso peruano en el lado boliviano.

\section{Tercer período}

En los años '70, mientras en Bolivia nacía el katarismo y poco después se iniciaba una serie de gobiernos militares, en el Perú la crisis arrastrada desde antes se agravaba aún más. El innovador Velasco fue derrocado en 1975 por otro militar más conservador que desautorizó su reforma. En 1980 retornaron los regímenes democráticos (Belaúnde, de nuevo, y en 1985 el aprista Alan García), que acabaron de desarmar las grandes empresas colectivas, aunque sin el retorno de los antiguos hacendados. Entre tanto, persistían las tomas de tierras por parte de pequeños productores y comunidades, que empezaron a concentrarse en la ocupación de esas empresas caídas. A todo ello, desde 1981 hasta 1992, se añadió la acción terrorista de Sendero Luminoso y, en menor grado, del MRTA (Movimiento Revolucionario Tupac Amaru), que dificultó en muchas "zonas de emergencia" el trabajo institucional del estado y otras instancias. Pronto el ejército entró también en el conflicto. De forma creciente reinó la inseguridad y el terror, por uno y otro bando, en muchas partes de la región andina, de la selva y poco a poco también en varias áreas urbanas.

El discurso de Sendero tenía muy poco de andino. Al principio suscitó cierto apoyo en el campo por el decidido ajusticiamiento de algunos abusivos y reclutó también adeptos sobre todo entre escolares campesinos. Pero su débil comprensión de la realidad comunal le llevó a ajusticiar a respetadas autoridades comunales y, cuando el ejército entró en el conflicto, sus duras sanciones a quienes no se ponían en su bando, lo alienó de la mayoría de los comunarios. Muchos fueron ejecutados o bien tildados de "terrucos" (terroristas) por parte del ejército o, si le colaboraban, de "soplones" por parte de Sendero. Pero la inmensa mayoría de los más de 20.000 asesinados durante los siguientes años ni eran "terrucos" ni "soplones" sino comunarios indefensos que no habían abandonado todavía sus comunidades. 
En 1990 empezó la era Fujimori, que dura hasta el momento de escribir estas líneas. Para nuestro relato resaltamos que, con su estilo a la vez duro y populista, logró desarticular a los grupos terroristas, aumentando la tranquilidad de la población; una de las cárceles de máxima seguridad se instaló precisamente en las alturas de Puno, en pleno límite del territorio aymara. Su política económica estabilizadora que elevó mucho el costo de vida, invirtió, una vez más, el sentido del contrabando fronterizo entre Perú y Bolivia.

Con este telón de fondo, volvamos a nuestro tema central, el pueblo aymara. Como en Bolivia, pero en tono menor, también los aymaras peruanos vieron expandirse nuevos instrumentos para dinamizar su cultura. En primer lugar, la Radio Onda Azul, en Puno, tiene una historia semejante a la de su hermana Radio San Gabriel en Bolivia. En los años '50 fue fundada por los PP. Maryknoll para apoyar una red de escuelas radiofónicas pero con el tiempo, sin perder su dependencia de la Iglesia Católica, se ha convertido en una de las principales emisoras para el mundo aymara, con una programación variada y buenos niveles de participación popular. Más recientemente se le han unido otras varias emisoras tanto religiosas (p. e., Radio Bahai) como comerciales e incluso se han creado programas en aymara para emigrantes en varias ciudades fuera del territorio tradicional aymara, como Tacna y Cusco. En la ciudad de Puno existen también centros e instituciones aymaras o pro-aymaras, aunque no llegan a formar una red tan vasta como la que se da en La Paz. Mencionemos la dinámica Academia de la Lengua Aymara ${ }^{14}$ y el Instituto de Estudios Aymaras (IDEA) en Chucuito, con numerosas publicaciones varias de ellas en aymara.

En el campo político, antes de la expansión de Sendero hubo ciertamente unos primeros intentos de movimiento katarista entre los aymaras de Puno, que escuchaban las radios bolivianas y tenían diversos intercambios a través de la frontera. En 1979, en Azángaro, dentro del área quechua del mismo de-

14 Cabe subrayar el rol desempeñado por el Aymara Project de la Universidad de Florida para los primeros contactos entre linguiistas aymaras de los tres países.

15 Este resumen se basa en Morin (1983). A pesar de la expansión del movimiento a otros sectores, en los documentos fundacionales del CISA en 1980 sólo aparecen aymaras como representantes del OBAAQ: pero esta sigla ya se pierde en otro documento de 1981. Ver Pueblo Indio (1982: 6 y 22; 1981 : 37). partamento, se fundó asimismo el Movimiento Indio Pedro Vilca Apaza, en recuerdo del principal héroe local de la rebelión anticolonial de los Amarus y Kataris. Emitió un Manifiesto que se inscribe dentro de una línea indianista semejante a la del MITKA boliviano (con el que tenía indudables contactos) y propone una "organización política de las nacionalidades quechuas-aymaras" para luchar por "la autonomía política, económica y social". El año siguiente figura ya entre los fundadores del CISA (Consejo Indio de Sudamérica), al que nos referiremos más adelante (en CISA 1980: 95, Pueblo Indio 1981: 37).

En la distante ciudad de Lima ocurrió en 1977 una especie de repetición en reverso del movimiento Huancho Lima (Huancané) de medio siglo antes, también bajo el liderazgo de aymaras inmigrados desde Huancané, al norte del lago Titicaca. Con ocasión del 150 aniversario de dicha provincia, organizaron en la capital una semana cultural y un festival folklórico en un coliseo, tradición corriente entre migrantes andinos de la ciudad. Pero lo nuevo fue que, al final, reclamaron al General Morales Bermúdez, entonces presidente de la República, el reconocimiento oficial de la lengua aymara, como su predecesor Velasco lo había hecho años antes con el quechua, y en 1978 organizaron el Primer Seminario de Lengua y Cultura Aymara, en el que participaron delegados de 27 organizaciones aymaras de la capital y también algunos aymaras de los otros dos países. Al concluir el evento, lanzaron la siguiente declaración panaymara: "Nosotros, aymaras de Bolivia, Chile y Perú, somos una nacionalidad, pues no hay fronteras que nos impidan buscar juntos nuestra liberación económica, cultural y social." El 4 de noviembre de 1978 crearon la Organización de Bases Aymaras (OBA) y declararon dicha fecha --aniversario del levantamiento de quechua Tupac Amaru, recuperado por la revolución velasquista-el "Día Anual de la Nación Aymara". Desde el siguiente año, 1979, el movimiento fue tomando otro rumbo más genérico "indianista": se amplió para formar la OBAAQ (Organización de Bases Aymaras, Amazonenses, y Quechuas), que el año siguiente, 1980, participará ya activamente en el movimiento continental CISA, arriba mencionado. Significativamente, en esta expansión, OBAAQ escogió el día 15 de noviembre, fecha en que se conmemora la inmolación del rebelde aymara Tupaj Katari, como "día internacional de las naciones autóctonas indígenas". ${ }^{15}$ Es decir, en su fase más 
aymara, se apeló a un héroe quechua pero del lado hoy peruano; y en la fase más amplia, se apeló a uno aymara aunque del lado hoy boliviano.

Pero estos primeros intentos se fueron diluyendo en los años siguientes con el agravamiento de la agitada situación política en el Perú, sobre todo a partir de la tensión e inestabilidad interna creada sobre todo durante la larga década (1981-1992) de guerra sucia entre los insurgentes maoistas de Sendero Luminoso (y, en menor grado, el MRTA) y el ejército contrainsurgente y las brutales represiones de ambos a las comunidades andinas. Esta situación general tensa es, sin duda, uno de los factores que explica porqué en la sierra y el altiplano peruano no ha llegado a florecer un movimiento aymara (ni quechua) semejante al de Bolivia y al de otros pueblos indígenas del continente. ¿Pero será ésta la única y principal explicación? En los años '80 tuve la oportunidad de conocer en el Perú a un alto dirigente de la CCP, que era precisamente un aymara originario de aquella comunidad que décadas antes había creado el nuevo pueblo Huancho Lima. En su discurso formal rechazaba explícitamente un enfoque que no fuera exclusivamente de clase, reiterando todos los temores de la izquierda clásica frente a lo étnico, por creer que conducía al racismo. Pero después, en la informalidad, surgía con fuerza su vivencia étnica, al hablar de la discriminación sufrida y de los valores de su pueblo y cultura. En Bolivia había ocurrido algo semejante hasta los años '60, pero desde los '70 se rompió la autocensura y empezó a proliferar un discurso también étnico, a igual que en otros países del continente. Pero las circunstancias especiales del Perú han seguido dificultando este cambio incluso en los años ' 90 , que ya no vienen marcados por el terror, y en que los dogmas de la izquierda clásica han perdido vigencia. ¿Qué otros factores influirán en ese bloqueo? Es un tema digno de análisis ulteriores más profundos, al que volveremos más adelante.

\section{Los aymaras chilenos}

Los asentamientos precoloniales de la actual área aymara de Chile eran sobre todo avanzadas en tierras de valle de ayllus mayores cuyos núcleos principales pertenecían a los señoríos aymara de Pakasa (Pacajes) y Karanka (Carangas) --hoy en Bolivia--, como parte de la lógica tradicional de sobrevivencia mediante el acceso a diversos pisos ecológicos. Pero, como vimos, desde la época virreinal habían estado ligados a Lima, fuera de la audiencia de Charcas, como parte del vasto corregimiento de Arica, del que después se desprendió también el de Tarapacá, al sur. En consecuencia, habían pasado a formar parte del estado peruano desde la Independencia. Pero en la vida cotidiana, persistían ciertos vínculos e intercambios con Charcas.

Con la victoria de Chile en la guerra del Pacífico en 1879 , todos estos territorios pasaron a formar parte de este país, que avanzó también por el este en una pequeña franja de altura que antes pertenecía a Charcas (Van Kessel 1992: 21-22). Todo el conjunto se llamó primero provincia de Tarapacá y, más recientemente I Región.

El nuevo gobierno chileno se esforzó ante todo en borrar los vínculos de esas comunidades con su anterior estado peruano y reforzar la chilenización acelerada de la población local, mediante una fuerte presencia de las nuevas instituciones estatales en el área recién anexada. Cabe subrayar que durante aquel conflicto bélico no hubo en esta región una mayor participación de los comunarios aymaras en el teatro de operaciones, a diferencia de lo ocurrido en el Perú cuando, conquistada ya esta parte del litoral, el ejército chileno fue avanzando hacia Lima y ocupó también la región andina central, dondé las comunidades quechuas amenazadas organizaron también su propia resistencia (Manrique 1981).

Por todas estas circunstancias, la historia de los aymaras chilenizados tiene su propio ritmo, muy distinto del de los que quedaron en Bolivia y Perú, por lo que aquí tiene menos sentido mantener los tres períodos utilizados en los dos casos anteriores. Basta hablar de dos, uno muy largo, que cronológicamente corresponde a los dos primeros de los otros países pero se alarga hasta 1990, en que concluye la dictadura militar de Pinochet, y otro que se inicia ya en los años de 1980 pero sólo se consolida con los gobiernos democráticos. ${ }^{16}$

\section{Primer período}

Se extiende desde 1879 hasta 1990 y se caracteriza aquí como la chilenización forzada de los aymaras. Esta política, iniciada con la conquista del norte

16 Para el resumen que sigue nos ha sido especialmente útil el libro de Juan Van Kessel (1992). 
grande y proseguida sin cambios significativos por lo menos hasta el fin de la dictadura de Pinochet (1990), ha consistido ante todo en establecer sólidas estructuras estatales en la región, desde municipios (o "comunas") hasta poderosos cuarteles de frontera, de acuerdo a los requerimientos de cada momento.

En las nuevas jurisdicciones estatales no se tuvieron muy en cuenta las anteriores unidades étnicas, cada vez más diluidas por otra clara política: la de desconocer allí la propiedad comunal y transformarla en familiar. Tal transformación no sólo era una expresión de la ideología general de la época, que tanto enfatizaba la importancia liberadora y modernizante de la propiedad privada. Tenía también la clara intención de debilitar los vínculos del pasado peruano. La comunidad aymara, al carecer de base jurídica en el nuevo estado conquistador, pasó automáticamente al fisco, que la fue asignando como pequeñas propiedades privadas a quienes las solicitaban y pagaban sus derechos, mayormente los antiguos comunarios que, una vez más, debían recomprar sus tierras ancestrales reconocidas ahora con esa otra modalidad privada. Es significativo que este proceso de eliminación de la propiedad comunal fue mucho más drástico en este territorio conquistado que en la región mapuche, al sur del país, donde de alguna forma, y no sin controversias, se reconocía la existencia de los llamados títulos de merced de la época colonial y donde a lo largo de la historia republicana la identidad cultural de este pueblo ha seguido pesando mucho más.

Como resultado de esta situación de postguerra, en contraste con el resto del mundo aymara, en estas regiones de Arica y Tarapacá, que además tenían una densidad poblacional mucho más baja, no encontramos la misma intensidad de resistencia, sublevaciones y subsiguientes masacres. El proceso se lleva adelante y logra su efecto. Por eso mismo, hay también desde un principio cierta semejanza con lo que, en los otros países, hemos considerado un segundo período, caracterizado por las reformas agrarias.

No debemos olvidar que el propósito de la guerra anexionista había sido lograr un pleno control de la riqueza principal de esa zona tan desértica. No se ambicionaba tanto su potencial agropecuario (limitado a los valles u oasis) sino sobre todo su potencial minero, expresado entonces en el salitre y, en menor grado, en el cobre y el azufre, más el complemento natural de todos ellos: los puertos de la costa. La conquista del llamado Norte Grande, por tanto, equivalió a la conquista del desierto, que desde varias décadas antes de la guerra ya se estaba llenando de oficinas salitreras y ferrocarriles de trocha estrecha, sobre todo en la llamada Pampa del Tamarugal, en las alturas de Iquique.

De cara a los aymaras, que se fueron concentrando (o refugiando) más en las partes altas, este desarrollo industrial supuso menos presión sobre la tierra. Fueron allí relativamente pocos los hacendados que ambicionaron sus frígidas tierras y los conflictos sociales más graves ocurrieron más bien entre las empresas salitreras y sus obreros, reclutados mayormente de otras regiones sureñas de Chile e incluso entre inmigrantes europeos y de otros países latinoamericanos. ${ }^{17}$ La participación aymara en las salitreras era mucho menor y sólo indirecta, para proveer leña, productos del campo, como arrieros y a lo más como peones mayormente temporales. Sobre las condiciones de vida de estos últimos, una comisión parlamentaria de 1913 dijo que eran "indígenas en estado de semi-barbarie, que tienen los peores campamentos, los más viejos, estrechos y desaseados y que viven en común con sus animales y duermen con ellos". ${ }^{18}$ Además de la evidente discriminación que éstos sufrían con relación a otros obreros, este texto trasluce también el racismo de la época, tan común en los tres países.

Si bien la expoliación de tierra no fue grave, lo que muchos aymaras sí sufrieron fue la expoliación de otro recurso básico y allí muy escaso, el agua, desviada para su utilización industrial o mercantil en las salitreras, en las minas o en empresas agrícolas de los oasis costeños. Este problema ha seguido persistiendo hasta el día de hoy afectando a las comunidades aymaras de altura tanto en Chile como incluso en Bolivia. Durante la dictadura de Pinochet se dictó una Ley de Aguas que da prioridad a ese uso mercantil a favor de las empresas que mejor paguen el acceso a este recurso, sin tomar en cuenta otros usos tradicionales (Mamani y Vilca 1989, Castro 1992). Tres décadas antes, el gobierno chileno

\footnotetext{
17 Sobre esos graves conflictos existen excelentes producciones artísticas como la "Cantata Santa María de Iquique" y la película "Actas de Marusia". Sergio González, de Iquique, ha documentado incluso el reclutamiento en Bolivia de quechuas cochabambinos.

18 Citado por Van Kessel (1992: 191 ).
} 
había ya desviado inconsultamente el río Lauca, aguas arriba de su entrada en territorio boliviano, privando de riego a comunidades aymaras del departamento de Oruro, en beneficio de empresas de la costa; el caso fue tan grave que llevó a la rotura de relaciones diplomáticas entre los dos países.

En el ámbito ideológico, el principal instrumento de chilenización ha consistido en dotar a la población de servicios públicos, muy particularmente de la escuela castellanizante y transmisora de toda la simbología oficial chilena. ${ }^{19}$ Este proceso fue más tardío, con una primera oleada en los años 1930 y una masificación final, que alcanzó también a las zonas de refugio en las alturas, entre 1950 y 1970.

Un segundo instrumento ideológico ha sido la predicación evangélica, que en las regiones de altura llegó con mayor intensidad que en los otros dos países, principalmente a través de las iglesias pentecostales. Estas se establecieron allí en 1960 y experimentaron un crecimiento notable desde los años' 70 , en que varias de ellas se articularon con el gobierno militar. Aunque no todos coinciden en este punto (ver Guerrero 1994), prevalece la impresión de que esta avalancha pentecostal ha contribuido mucho a la chilenización con pérdida de la cultura aymara. Pero hay que reconocer al mismo tiempo, que esta actitud misionera y cuestionadora de la tradición, brinda, a muchos que la adoptan, una oportunidad única para tener un protagonismo que antes se les negaba y, en bastantes casos, una mejor economía, en una micro-versión de lo que Max Weber había observado en la ética protestante y el capitalismo.

En las últimas décadas, y muy particularmente durante la dictadura militar de Pinochet (1973-1990) el Estado siguió acentuando todas estas tendencias "aymaracidas", combinadas con un esfuerzo notable de mejorar la infraestructura y servicios básicos y fortalecer nuevos centros administrativos intermedios. El auge del salitre ya se había eclipsado desde los años 40, pero en esta última fase fue sustituido por el desarrollo espectacular de polos urbanos en la costa, primero Arica y después Iquique, gracias a su condición de "zona franca" sobre todo para canalizar importaciones desde el Japón, muy particularmente a Bolivia, de cuyos puertos depende. Este crecimiento urbano ha dado también un cierto respiro económico al deprimido altiplano boliviano de Oruro, no sólo por ser la puerta de entrada de la zona franca costeña sino también como nuevo mercado para exportar productos de altura, como la quinua y la carne de llama, que es actualmente más consumida en Arica e Iquique que en las ciudades bolivianas.

La gran mayoría de los aymaras de las alturas ha emigrado a estas ciudades costeñas. Son también bastantes los aymaras (y chipayas) del altiplano boliviano que bajan a la costa o a las empresas agrícolas de los valles interandinos como trabajadores temporales, para actividades comerciales o, poco a poco, para establecerse de manera indefinida.

El resultado más patente de este largo proceso para los aymaras de la región es lo que Van Kessel (1992) ha llamado su "holocausto al progreso"; un holocausto en parte buscado y aceptado por esa misma población que tan marginada se había sentido durante décadas. La mayoría de los inmigrantes urbanos definitivos, efectivamente se ha chilenizado, pero por la vía de la transculturización --la única que se le brindaba--, cautivada por esas sirenas del progreso, en un grado mucho mayor de lo que había ocurrido en Perú y Bolivia durante la fiebre campesinista de las reformas agrarias pero muy semejante al que se da en tantos serranos peruanos trasladados a Lima y a otras ciudades de la costa. En el caso de los inmigrantes bolivianos, la autonegación debe dar un paso más, negando u ocultando también su origen extranjero. Aunque paradójico, resulta significativo que en el plebiscito de 1988 en toda esta región ganó el "sî" a favor de Pinochet, el que más se había esforzado para negar la identidad aymara porque, como él mismo decía, "en [su] Chile no hay indígenas; sólo hay chilenos".

\section{Segundo período}

Se caracteriza, como en Bolivia y otros muchos países del continente, por el resurgimiento de lo étnico, en nuestro caso de lo aymara (Albó 1991). No supone un cambio global en toda la tendencia anterior pero es suficientemente significativo para que le dediquemos un espacio propio. El historiador José Bengoa, que a principios de los años '90 dirigió la comisión para la nueva Ley Indígena llegó a expre-

19 El estado boliviano hizo algo semejante al crear escuelas, más temprano que en otras partes, en comunidades del altiplano fronterizas con Perú y Chile, sobre todo después de sufrir su segunda derrota internacional en el Chaco. 
sar que este era uno de los cambios más notables en la historia indígena de Chile. ${ }^{20}$

Se inicia ya en los años ' 70 , por una múltiple confluencia de coyunturas. Por una parte, el golpe de Pinochet en 1973 expulsó hacia la región a un número inusual de investigadores salidos del sur y con ellos surgieron nuevas ONG interesadas en la temática aymara tanto en el campo académico ${ }^{2 \mathrm{l}}$ como en diversas actividades de promoción. Aunque su relación con las bases aymaras tuvo ciertas ambiguiedades, suscitó sin duda un repunte en el interés por esos asuntos hasta entonces poco prestigiados. Por otra parte, existían ya algunos intelectuales y artistas aymaras locales. Es también indudable la influencia de algunas radios aymaras bolivianas, que llegaban bien a ese lado de la frontera; por ese medio y por algunos contactos personales se supo también del movimiento katarista boliviano. Con todos estos antecedentes, y no sin cierto tono competitivo frente a las ONG, desde 1986 empezaron a surgir diversas organizaciones culturales aymaras como Pacha Aru en la ciudad de Arica y Aymara Marka en la de Iquique y, desde ahí, en algunas comunidades de altura. Todas ellas intentaron incluso agruparse en una Federación de Organizaciones Aymaras, pero sin mucho éxito.

En 1990 retornó la democracia y con ella se inició una nueva actitud del gobierno frente a la cuestión indígena, influenciado sin duda por las nuevas corrientes mundiales más favorables al pluralismo étnico. Ya en la previa campaña electoral varios dirigentes aymaras habían tenido un rol protagónico en una iniciativa llamada el Partido por la Tierra, que participó en las elecciones aliado a otro partido menor y aumentaron también sus contactos con el movimiento mapuche. Los resultados electorales no fueron alentadores, pues todo el país estaba más polarizado en el tema nacional de prolongar o cortar el sistema anterior. Pero, en otros ámbitos, los esfuerzos combinados de aymaras y mapuches no fueron vanos. El nuevo gobierno de Aylwin aprobó una ley indígena y creó instancias especializadas dentro de la administración pública, en las que se incorporaron varios de los aymaras que pocos años antes habían iniciado el movimiento reivindicativo.

20 Comunicación personal.

21 Entre 1960 y 1973 se registran apenas 16 publicaciones sobre ciencias sociales de la región. Pero en sólo los cuatro años siguientes ya se producen 34 y en los años siguientes la proporción va en aumento (Van Kessel 1992: 294-295).
También en el campo educativo se empezó a hablar de algo hasta entonces inaudito en el norte chileno: la educación intercultural bilinguie, llegando a crearse dicha especialidad en la universidad estatal de Iquique.

En este desarrollo sobresale el rol de ciertas elites aymaras urbanas cuyo paso a la ciudad no borró sino más bien estimuló su identidad ancestral. Es un fenómeno semejante al que se ha dado también en la ciudad de La Paz y, dentro de Chile, con los mapuches urbanos de Temuco y Santiago. En él se observa también --como en Bolivia-- una doble corriente: una más ideologizada e indianista, con una influencia explícita de la rama katarista indianista boliviana; y otra más cercana a la problemática socioeconómica de la población. También aquí los primeros son más urbanos y tienen menor contacto con la realidad cotidiana del agro aymara mientras que los segundos mantienen vínculos más estables con éste.

La recuperación de la identidad aymara en Chile sigue siempre marcada por la anterior historia de chilenización forzada. En una ocasión unos dirigentes aymaras chilenos comentaron: "Si decimos que somos aymaras, nos insultan: nos llaman bolivianos". De ahí, también su manera de enfocar su reivindicación: "Somos chilenos, pero aymaras."

Esta tensión más fuerte de los aymaras chilenos llega a repercutir incluso dentro de Bolivia. Un análisis sociolinguústico del censo de 1992 muestra que en este país uno de los grupos rurales aymaras más avergonzados de su origen, o al menos de su lengua materna, son los que viven cerca de la frontera de Chile, en buena parte por la dura experiencia que sufren cuando acuden a este país como trabajadores eventuales (Albó 1995: I, 1104-105, 109).

\section{Allende y aquende las fronteras}

Bajo este título, retomado de un documento del Parlamento de la Nación Aymara (1996), aquí volveremos a los tres períodos históricos mencionados en las páginas anteriores para centrarnos más en los intercambios entre los aymaras de los tres países. Pero antes, como telón de fondo, señalaremos algunos intercambios y contactos de tipo tradicional que se han dado desde tiempos ancestrales y persisten, con sólo adaptaciones coyunturales a la situación de cada país, hasta el presente. 
Los intercambios tradicionales

El caso más típico, con raíces en un pasado remoto, es la relación entre algunas comunidades altiplánicas y los valles y yungas subtropicales, independientemente de que ahora estén separados por fronteras internacionales. En tiempos más recientes, las ciudades se han añadido como un nuevo nicho socioecológico al que los comunarios desean también tener acceso. Este permanente interacción entre estas zonas diversificadas ha sido ante todo para intercambios de tipo social y económico, dentro de la conocida estrategia ancestral andina de buscar acceso complementario a diversos pisos ecológicos. Aparte de los negociantes, que se mueven en todas direcciones, los principales flujos de gente han sido sobre todo de las alturas hacia las tierras bajas, para tener acceso a productos complementarios de la dieta y como mano de obra temporal. Por lo mismo, ha sido más común la presencia de aymaras del altiplano peruano en Bolivia (a los valles, a los yungas y a la ciudad de $\mathrm{La}$ Paz) que viceversa. En cambio, con relación a Chile, lo más común ha sido la migración temporal o definitiva de aymaras del altiplano orureño, hacia los valles agrícolas y, de ahí, a las ciudades de Arica e Iquique.

Con relación al intercambio entre aymaras de Perú y Bolivia, en tiempos recientes hemos podido constatar la persistencia de estos vínculos interecológicos sobre todo en la parte noroeste del lago. Una primera forma, muy persistente hasta hoy, era --y es-- a través de los trueques de productos de cada piso ecológico sobre todo por viajes de gente del altiplano peruano a los valles mesotérmicos al norte de La Paz. Los primeros llegan sobre todo con lana y allí la cambian por maíz. Actualmente, aunque en este intercambio no se utiliza dinero, los términos del intercambio varían según la cotización de las dos monedas, pues la lana no proviene necesariamente de los propios rebaños sino que se ha comprado previamente en efectivo en la feria de Juliaca (Puno) u otras. En esos trueques no es raro que se den, además, situaciones de bilingüismo pasivo entre los aymaras altiplánicos y los vallunos, que en partes de esa zona son de habla quechua. Cada uno habla en su lengua, sin poderlo hacer en la otra, pero ambos se entienden perfectamente.

Una segunda forma, ahora ya poco común, es hacia las tierras productoras de coca en los yungas de La Paz, bastante más distantes. En los años '30, duran- te la guerra del Chaco, hubo voluntarios aymaras peruanos que acudieron al campo de batalla, en el otro extremo del país, y acabada la contienda recibieron en compensación tierras en yungas. Hasta los años '80 en Coripata se los conocía como "los peruanos" y algunos de ellos se habían transformado en prósperos negociantes. Algo más allá, hay otra comunidad, llamada Apa Apa, cuyos orígenes parecen ser semejantes.

En cuanto a los intercambios entre el altiplano de Bolivia y los valles de Chile, es evidente que estos existían desde antes. Por ejemplo, la tradición cuenta que la imagen del santo patrón de Turco (Oruro) proviene de los valles de Camiña (hoy Chile). Pero la conquista militar y subsiguiente penetración del estado y los intereses económicos chilenos en estas tierras bajas ha modificado algo el estilo y fluidez de estos intercambios. No se ha perdido en absoluto, pero ahora tiene mucho más semejanza con otras migraciones laborales temporales hacia zonas de economía capitalista; y en ellas, es mucho más común que los aymaras y chipayas procedentes del altiplano orureño intenten camuflar su origen para evitarse problemas.

A otro nivel, no sabemos desde cuánto tiempo atrás, hay también otros muchos intercambios de tipo artístico y folklórico, por ejemplo con ocasión de las principales fiestas, desde las típicas alasitas ${ }^{22}$ de cada pueblo hasta otras mayores como las impresionantes manifestaciones folklóricas con ocasión de la Candelaria de Puno (Perú), el Gran Poder de La Paz (Bolivia) e incluso la fiesta de La Tirana, en la Pampa del Tamarugal (Iquique, Chile). Sobre todo en las dos primeras, es principalmente el gremio ya muy bien establecido de los artesanos paceños el que saca los mejores dividendos. Pero, en términos simbólicos, todas estas fiestas, grandes o chicas, son una excelente ocasión para reforzar elementos culturales comunes.

Con este telón común de fondo, pasemos a describir otros tipos de intercambios más propios de cada período histórico.

22 Celebración. muchas veces vinculada a la fiesta patronal, cuyo rito principal es el intercambio o compraventa de objetos de todo tipo en miniatura (desde alimentos, artículos culinarios o animales hasta casas, vehículos, dólares de alto corte, títulos universitarios o pasajes aéreos) cuya adquisición e intercambio en estas fiestas preludian su adquisición real en el futuro próximo. 
Primer período

Lo más propio de esta época, marcada en Perú y Bolivia por la expoliación de tierras y la resistencia, son los intercambios extraordinarios en momentos de rebelión entre comunarios rebeldes de ambos países. En cambio las comunidades del sur, recién conquistadas militarmente por Chile, vivían otra coyuntura que no les permitía hablar de rebelión ni resistencia.

Recordemos, como punto de partida el movimiento cacical de principios de siglo en Bolivia. En este país los nuevos "caciques" aymaras adoptaron este título colonial cuando lo descubrieron en títulos coloniales de tierras, que fueron a buscar hasta la distante Lima, saltándose las fronteras estatales (Ticona y Albó 1997: 96-100). Y fue probablemente en el curso de estos viajes que se establecieron vínculos entre rebeldes bolivianos y peruanos que luchaban todos por una misma causa.

Llanque ha encontrado, efectivamente, a través de relatos orales, algunas evidencias de estos contactos. Por ejemplo, le contaron que algunos comunarios pasaban de uno al otro lado de la frontera, para escaparse o incluso para circular mensajes secretos camuflándolos dentro de la costura del poncho. ${ }^{23}$ En el caso concreto de Jesús de Machaqa --a pocas leguas de la frontera, en el lado boliviano-- hay también testimonios de que los alzados preparaban la munición de forma casera con insumos conseguidos en el Perú, tanto con ocasión de la sublevación "cacical" de 1921 como en el de conflictos internos previos entre ayllus (Choque y Ticona 1996: 283). Más significativo aún, en medio de estas sublevaciones más inmediatistas y locales surgen las primeras propuestas de restauración o autonomía política, como las de Juan Lero (1899) y sobre todo las de Eduardo Nina Quispe (1930) en Bolivia, y la de Rumi Maki en Puno, que ya plantearon respectivamente, siquiera como una utopía en clave de pasado, la República del Qullasuyu y el Gobierno Socialista del Tawantinsuyu.

Surge en este período otro tipo contactos estimulados desde afuera, a través de la penetración de algunas iglesias evangélicas en el mundo aymara. El caso más antiguo y significativo es la difusión de la religión adventista a partir de su cabeza de puente en el

23 Comunicación personal. altiplano puneño. El centro de difusión adventista fue una escuela y, a través de ella, la creación de un nuevo pueblo "indígena" en Platería, cerca del pueblo mestizo de Chucuito ya en 1913. Desde allí y en competencia con este último, se empezaron a difundir tanto su mensaje religioso como un enfoque más "modernizante" que ponía énfasis en la educación del indio. Se expandió la predicación y la construcción de capillas y escuelas rurales por las comunidades rurales a un lado y otro de la frontera con bastante intercambio mutuo (Hazen 1974: 38 sgtes; Ticona y Albó 1997: 163-166). El principal vínculo común aymara era allí la lengua, pues la nueva fe debilitaba e incluso rechazaba otros aspectos culturales, sobre todo en la esfera religiosa y ceremonial.

Medio siglo después ha ocurrido un flujo del altiplano chileno hacia Bolivia, que, pese a la distancia en el tiempo, tiene muchas semejanzas estructurales. Nos referimos a la iglesia pentecostal, arriba mencionada, sobre todo a la rama que se articuló con el gobierno militar. Como había ocurrido medio siglo antes con los adventistas de Platería, Perú, estos pentecostales militantes cruzaron pronto la frontera boliviana, en este caso por Sabaya, Oruro, y desde allí han ido difundiendo su credo hasta puntos alejados del trópico (Rivière 1988).

Las versiones más proselitistas y fundamentalistas de tal acción misionera tienden a acelerar la pérdida de la cultura aymara. Pero hay que reconocer también que muchos adoptan la nueva fe, sin perder totalmente su identidad aymara, como una oportunidad única para acceder a la educación formal, tener un protagonismo que antes se les negaba y, en ciertos casos, una mejor economía, en una microversión de lo que Max Weber había observado en la ética protestante y el capitalismo. No dejan de sentirse aymaras, aunque "blanqueados" (StroebeleGregor 1989).

\section{Segundo período}

El enfoque campesinista y nacionalista de este período no estimuló nuevas formas específicas de vinculación entre los aymaras de los tres países. Seguían los intercambios habituales entre aymaras en torno a la frontera y, en cierta medida, incluso se ampliaron como resultado de la mayor actividad comercial de los aymaras bolivianos, liberados ya de la hacienda. Dentro de las nuevas ferias campe- 
sinas que empezaron a proliferar por el altiplano, surgieron también varias en plena frontera, como Ninantaya, al norte del Lago, Desaguadero --la más desarrollada de todas-- y "La Tripartita", en el extremo sur, donde confluyen las fronteras de Perú, Bolivia y Chile.

Se cuenta que en esta última --ubicada en un lugar particularmente alto, frío y desértico-- se realizaron incluso, en ciertas épocas, wilanchas o sacrificios rituales de llama a las banderas de los tres países, porque era precisamente esta situación tri-fronteriza la que daba vida a los aymaras del contorno; se añade que hubo una cancha "internacional" de fútbol en la que para meter gol había que cruzar la triple frontera. Ciertos o no, estos relatos muestran la creciente importancia del comercio y el contrabando hormiga de subsistencia en la línea fronteriza sea en esas ferias o en las mil rutas en bote por el lago y el sentido de continuidad humana, lingüística y cultural más allá de la frontera, aunque tal vez no nos permiten deducir aún una clara conciencia de territorio aymara compartido. Más abajo volveremos a esta "Tripartita".

\section{Tercer período}

Este es sin duda el más fecundo para nuestro tema. Empezaremos reseñando las nuevos intercambios en el ámbito cultural, más tempranos e intensos, y de ahí nos pasaremos a los que tocan además la esfera política, más tardíos pero también más significativos.

Dentro del ámbito de la cultura aymara, uno de los primeros y más continuados intercambios trinacionales con contenido reivindicativo cultural ha sido el generado por las radios aymaras, muy particularmente Radio San Gabriel, en el lado boliviano, aunque hay muchas más de menor potencia. En conjunto, aseguran una amplia audiencia aymara sobre todo en Perú y Bolivia y, mediante sus programas, informativos, mensajes participativos de la audiencia, música, etc., han contribuido significativamente a generar un sentido amplio de pueblo aymara a ambos lados de la frontera y hacia Chile, que no tiene emisoras en esta lengua. Es típico, por ejemplo, que se pongan de moda los waynitos peruanos entre los aymaras de Bolivia y determinados conjuntos bolivianos en el Perú. Pero, pese a las restricciones institucionales o ideológicas de cada medio, éste es además el medio por el que más fá- cilmente se han difundido nuevas corrientes reivindicativas del pueblo aymara. En tiempos de represión no han faltado tampoco programas y mensajes emitidos desde el país más libre pero elaborados y dirigidos al otro.

Desde fines de los años ' 60 fue pionera también la que vino en llamarse "Iglesia Aymara", de un estilo notablemente distinto del de los movimientos adventistas y pentecostales arriba señalados. Este era un movimiento de mayor inculturación, fomentado por ciertos sectores de la Iglesia Católica renovados por el Concilio Vaticano, por los documentos del CELAM en Medellín y posteriormente también por la Teología de la Liberación, uno de cuyos primeros sistematizadores ha sido el peruano Gustavo Gutiérrez, gran admirador de José María Arguedas. Ha involucrado a sacerdotes, religiosas y a varios obispos, pero también a una red numerosa de "catequistas" tanto en el lado peruano como en el boliviano. Se han llegado a realizar así diversos tipos de encuentros binacionales de lo que enseguida se llamó la Iglesia Aymara, a uno y otro lado de la frontera (Jordá 1981). Después se ampliaron ocasionalmente a los quechuas, a otros países andinos (norte de Chile y Ecuador) y, en algunos casos, a representantes de otras denominaciones religiosas históricas, como luteranos y metodistas. Pero el núcleo principal han seguido siendo los aymaras de Perú y Bolivia. Su temática también se ha ido ampliando: del uso creativo y compartido de un lenguaje y música aymara, se pasó a la adopción de rituales culturalmente más acomodados; y de ahí, a la formación de iglesias aymaras locales y a otros asuntos tanto teológicos como sociales, con enfoques a veces muy cercanos a los del katarismo; de la reflexión aymara a la teología andina y de ahí a la llamada teología india.

Otro campo cultural privilegiado para el intercambio entre aymaras de los tres países ha sido el de los estudios lingüísticos. Pionera en este campo fue la Dra. Martha Hardman de Bautista y su Aymara Program en la Universidad de Florida (USA). Ya en los años '60 apoyó la formación académica de aymaras de los tres países para el estudio de su lengua y creó en La Paz el Instituto de Estudios Linguísticos, todo lo cual ha sido la base para los primeros intercambios entre aymaras de los tres países en un tema tan central para su identidad común, como es la lengua. A partir de esta base o por otras vías autónomas, han surgido, entre otros, el 
Instituto de Lengua y Cultura Aymara (ILCA) en Bolivia, diversos cursos y boletines en Arica (Chile), y la Academia de Lengua Aymara en Puno y el Instituto de Estudios Aymaras (IDEA) en Chucuito (Puno), con numerosas publicaciones varias de ellas en aymara. Se han realizado cursos de aymara dentro y fuera de las universidades públicas, se han publicado estudios académicos y otros textos más populares, se han llevado a cabo varios encuentros internacionales sobre lengua aymara con participación de delegados aymaras de los tres países, etc. No es pues de extrañar que también los aymaras más políticos hagan permanentes referencias a la temática linguiística que los identifica y une a través de las fronteras.

Más recientemente, y a un nivel más estatal, la experiencia combinada del postgrado de lenguas andinas en la Universidad Técnica del Altiplano en Puno (desde los años ' 80 ) y de la actividades más prácticas de Educación Intercultural Bilingüe (EIB) primero en Puno y desde 1990 también en Bolivia tuvo otro efecto práctico en la creación del PROEIB (1997), un programa de maestría en educación intercultural bilinguie para todos los países andinos, con sede en la ciudad de Cochabamba, Bolivia, y dirigido por quien años antes había fundado el mencionado postgrado de Puno. Entre las universidades asociadas, con programas de lengua y educación aymara, están la de Iquique y la de Puno. Es ésta una de las instancias institucionalizadas más estables en que gente andina de diversas culturas tiene la oportunidad de conocerse a un lado y otro de las fronteras. Como resultado han surgido dos corrientes, al menos entre los participantes aymaras: ${ }^{24}$ unos intercambian más entre ellos, de una región aymara a otra, en los tres países; pero la mayoría amplía más bien el horizonte hacia una causa indígena común pluriétnica.

Pasemos al campo de la política aymara. Dentro de las dos grandes corrientes que hemos percibido, sobre todo en Bolivia, la que más ha fomentado los intercambios entre los tres países ha sido la indianista, quizás por tener una base más urbana y un enfoque más ideológico. Pero ha sido por lo general un contacto sólo entre cúpulas. La otra corrien-

24 Participan actualmente 9 aymaras (de los que 4 son mujeres) provenientes de Bolivia (4), Perú (3) y Chile (2), junto con quechuas de tres países, mapuches de Chile, páeces de Colombia y otros. te, más abierta a los demás actores sociales, sigue siendo la que en cada lugar mantiene más contactos entre líderes y bases pese a sus indudables limitaciones. ¿Será por mantenerse más cercana a las organizaciones locales y a la problemática más inmediata de cada lugar?

Este intercambio ha sido de diversa intensidad y contenido según los países y las coyunturas. Aunque más tempranas, las influencias más débiles han sido entre Bolivia y Perú. Más allá de los escarceos iniciales ya mencionados, entre 1979 y 1981, ni ha habido un sólido trasvase de algo parecido al katarismo, indianista o no, en el lado peruano ni tampoco de la violencia senderista en el lado boliviano. El tema es complejo y difícil de interpretar, pero las siguientes reflexiones pueden ayudar a ello.

¿Por qué el fuerte movimiento aymara boliviano no ha llegado a transvasarse en el lado peruano, ni siquiera años después de haber concluido la pesadilla senderista? Ha habido, sin duda, movimientos indianistas también en el Perú y, como vimos, fue precisamente allí donde en 1980 se fundó el Consejo Indio de Sudamérica y funcionó su primera sede. Pero en los años posteriores, no parece que estos intentos hayan tenido un peso semejante al que tienen en La Paz ni mucho menos hayan logrado generar una significativa corriente étnica dentro de las organizaciones "campesinas" serranas. ¿Por qué?Ya lancé estas preguntas en Albó (1991) y las reitero casi siempre que me encuentro con algún sociólogo, antropólogo o politólogo peruano. Carlos Iván Degregori (1995) es el que hasta ahora ha recogido mejor el guante. Enfatiza sobre todo la distinta evolución de la formación económica, social y política de su país, con el peso específico que en ella tiene Lima y la Costa. Casi todos los consultados subrayan también la importancia de las emigraciones masivas de la Sierra a la Costa, particularmente a Lima, que ya supera los 7 millones, y el rechazo de la mayoría de estos inmigrantes a ser identificados como "indígenas", pese a los vínculos que muchos de ellos mantienen con sus lugares de origen; éstos al parecer influyen más bien para que algunos comunarios se resistan también a este tipo de denominaciones étnicas.

Tampoco ha habido influencias significativas en sentido contrario. Muchos se siguen preguntando, por ejemplo, por qué movimientos como Sendero Luminoso y el MRTA, tan activos en el sur andino 
peruano, no lograron cuajar en la vecina Bolivia, que sufría crisis económicas y sociales muy comparables a las de aquel país. ¿Qué rol puede haber tenido en ello el común territorio aymara, que constituye la bisagra natural entre ambos países?

La acción de Sendero y del ejército llegó también al departamento fronterizo de Puno, aunque tardíamente; en 1986 llegó a ser el tercer departamento más afectado por los atentados (mayormente en su área quechua) pero el año siguiente volvió a bajar al treceavo puesto (DESCO 1989). Según varios analistas este poco éxito de Sendero se debió a que tanto allí como en el vecino departamento del Cusco, los comunarios se encontraban mejor organizados. Uno de los primeros globos sonda de Sendero en la región aymara fue su atentado contra el Instituto de Educación Rural de Juli. Pero la protesta de las organizaciones populares y de instancias de solidaridad de la iglesia local fue tan rápida y masiva, que se logró neutralizar ulteriores acciones y precautelar las del ejército.

Tal vez esta situación explica también por qué los senderistas no utilizaron mayormente el territorio boliviano como su punto natural de expansión o refugio, salvo de forma sólo ocasional. ${ }^{2.5}$ En general, se puede afirmar que el tejido social, pese a sus reconocidas deficiencias, se ha mantenido mejor en Bolivia, y sus organizaciones de base, incluidas las aymaras, siguen cumpliendo su rol de interlocutores y mediadores, por lo que se ha logrado evitar una polarización desesperada como la que en el país vecino generó a Sendero Luminoso.

El caso del MRTA es ahí algo distinto. En nuestra región aymara se mantuvo en un perfil bajo, sin acciones notorias, pero sí tuvo cierta influencia ideológica en algunos jóvenes alcanzando incluso al lado boliviano. ¿Tendrá algo que ver la referencia explí-

25 Los principales intentos se dieron al norte del lago, colindante con el pueblo peruano de Moho que fue objeto de varias acciones senderistas. Primero se habló intrusiones senderistas en Ulla Ulla. Poco después y algo más adentro en territorio boliviano unos desconocidos dinamitaron un monumento religioso --algo insólito-- y en los valles colindantes corrieron rumores de que cierta ONG del área tenía vínculos senderistas. Lo extraño de esta acusación, totalmente infundada, es que esta misma ONG acababa de sufrir en el Perí dolorosos asesinatos por parte de Sendero. Todo ello motivó varias notas de alarma en la prensa y cierta movilización del Ejército fronterizo, más asustado que eficiente, pero todo se apagó por sî solo sin necesidad de mayor acción. cita al héroe colonial Tupaq Amaru?

En el contorno de La Paz surgieron efectivamente algunos pequeños grupos terroristas, inspirados sin duda en los dos que existían en el Perú pero sin articulación orgánica con ellos. En su mayoría. se trataba de sectores urbanos, aunque varios apelaron también a la emblemática figura de Tupaq Katari. Sólo uno de ellos, llamado primero Ofensiva de los Ayllus Rojos y después Ejército Guerrillero Tupaj Katari, llegó a tener militantes aymaras rurales sobre todo en la región lacustre que por el norte colinda con Moho. El líder principal de este sector, Felipe Quispe o "El Mallku”, participó activamente en varios eventos de la CSUTCB y al mismo tiempo en diversos atentados, por ejemplo, contra torres eléctricas, por los que fue detenido y recluido varios años en la cárcel. Pero la violencia de su pequeña organización era nada comparada con la de los casos peruanos. Más aún, ya fuera de la cárcel, en 1998, una crisis interna de liderazgo dentro de la CSUTCB fue superada eligiendo por unanimidad, como máximo ejecutivo de esta organización, al Mallku. Su retórica agresiva contra los q'aras (o blancos) apela a las bases pero ahora sus acciones han entrado en la lógica democrática del diálogo.

En cuanto a las relaciones políticas entre los aymaras de Chile y los de los otros dos países, estas han sido más tardías, por las coyunturas históricas de este país, pero una vez establecidas, son más fáciles de explicar. Siendo una minoría tan clara, los sectores aymaras más militantes de este país, se sienten mucho más obligados a dirigir la mirada a los de los otros países, particularmente a los de Bolivia que son más y están más activos. Su despertar étnico ya tuvo que ver con las noticias de movimientos semejantes en Bolivia, que les llegaban sobre todo a través de las radios de este país. Más adelante, han participado en diversos eventos bi o trinacionales, en varios de los cuales ellos mismos han sido los anfitriones.

En los años recientes, las dos principales instancias en que se han encontrado formalmente aymaras de los tres países, han sido el llamado Seminario Amáutico del Area Andina y el Parlamento de la Nación Aymara.

El alma del Seminario Amáutico es el sociólogo aymara boliviano Simón Yampara Huarachi, que en el pasado fue activo militante en el movimiento 
katarista, llegó a ocupar el cargo de Ministro de Asuntos Campesinos y Agricultura y posteriormente fundó CADA y desde allí se ha concentrado más en la reflexión sobre una filosofía aymara y andina. Entre 1990 y 1993 ha habido cuatro sesiones internacionales del seminario con participación de connotados intelectuales y políticos sobre todo aymaras de los tres países, más algunos quechuas. La más substantiva de las sesiones ha sido la tercera, reunida en 1992 pocos meses antes de las conmemoraciones del V Centenario, con ponencias que van desde temas históricos, que enfatizan la persistente resistencia aymara, hasta otras para una filosofía propia ("saber aymara") que prepare el camino para la propuesta política de "reconstrucción de la nación aymara contemporánea" (Yampara 1993). El abogado aymara Jesús Alarcón, de Tacna (Perú) es quizás el más explícito con relación al camino político a seguir. Percibe tres corrientes principales dentro de los intelectuales: la primera, que considera más vigente en los aymaras chilenos, es "conseguir una legislación que les permita desarrollarse respetando sus valores ancestrales, lo cual implica reconocer tácitamente la autoridad criolla". La segunda, más presente en los kataristas bolivianos, prioriza "formar un partido aymara que actúe en política, se enfrente a los partidos de los criollos y asuma el poder político de los estados". Finalmente, la tercera, que él atribuye a sus paisanos peruanos, consiste en "la resistencia pasiva de no participar en política con partido propio, dejando que los gobiernos criollos solos se convenzan de su mediocridad en gobernar a los aymaras". Al final, concluye:

\section{"En todo caso, cualquiera de estas tres corrientes apuntan al logro de un autogobierno que tendrá que pasar necesariamente por un proceso democrático interno y por etapas previas que tengan su inicio en, primero hacer reconocer la Nación Aymara, como integrante constitucional de los Estados La- tinoamericanos, quienes tendrán que declararse estados plurinacionales, pluriculturales y}

26 En Yampara (1993: 87-88). Salvo por el tema de nación aymara y estado plurinacional, temas que siguen levantando ronchas entre los legisladores criollos, varios estados ya han hecho reformas constitucionales en la línea señalada por Alarcón.

27 Ver el mapa 3, producido por el mismo Parlamento.

28 Se puede consultar http://www.puebloindio.org/ceacisa.htm, http://www.puebloindio.org/CISA/CISA estatut.htm, y los e-mail evocat@puebloindio.org y, para el Parlamento del Pueblo Aymara, arsuri@caoba.entelnet.bo. multilingües. Esto implica una reforma constitucional a nivel continental en cada uno de los Estados" 26

Lamentablemente, como tantas otras iniciativas, la de estos seminarios amáuticos se desinfló despues de las celebraciones del V Centenario, entre otros motivos por la falta de recursos, aunque quienes participaron en ellos siguen manteniendo ciertos vínculos entre sí.

De alguna manera, la batuta la intentó tomar posteriormente el llamado Parlamento de la Nación Aymara, creado por iniciativa de algunos individuos de Perú y Bolivia vinculados con el antiguo CISA. En julio de 1996 y de 1998 tuvieron dos sesiones con participantes de los tres países, realizadas ambas en el punto en que confluye la frontera tripartita de éstos, al que han dado el nombre simbólico de Taypiqala "la piedra central". Su principal punto de interés ha sido la defensa del agua, la ecología y el medio ambiente en la cuenca interna conformada en torno a los lagos Titicaca, Poopó y los salares de Coipasa y Uyuni, ${ }^{27}$ a la que llaman "hábitat milenario del pueblo aymara", y a la que sienten amenazada sobre todo por los macro proyectos de trasvase de aguas hacia los valles de Perú y Chile.

El propio CISA ha intentado reorganizarse, en una "asamblea estatuaria" realizada a fines de enero de 1998 en la bella isla Taquile del lago Titicaca, "donde se siente el espíritu de Mallku Qhapaq y Mama Ajlla, convertido en brisa lacustre". Hubo cuatro participantes de Bolivia (uno de ellos, del mencionado Parlamento del Pueblo Aymara), uno de Jujuy, al norte de Argentina, y los otros 29, del Perú, casi todos aymaras y quechuas del departamento limítrofes de Puno. Los estatutos aprobados ratifican los principios indianistas de la reunión de Ollantaytambo en 1980 y se decidió establecer la sede del nuevo CISA en la ciudad de Puno. Es evidente que, más allá de la referencia a "Sud América" en esta sigla, su nueva convocatoria quedaba mucho más reducida al contorno del lago sagrado.

Tanto el Parlamento Aymara como este nuevo CISA altiplánico se han dado incluso a conocer por internet ${ }^{28}$ y buscan una instancia de cabildeo ante las Naciones Unidas, gracias a los antiguos ví_culos internacionales del primer CISA. Pero su principal problema es su falta de representatividad ante el conjunto de la población aymara y sus organizaciones de base en los tres países mencionados. Se- 
gún consultas recientes realizadas con éstas últimas en Bolivia y Chile, sigue siendo una actividad de unos pocos individuos y de sus pequeñas organizaciones locales, sin mayor coordinación con el resto. Sigue habiendo ocasionales viajes e intercambios de individuos y organizaciones a un lado u otro de estas fronteras y no faltan tampoco otros esporádicos portavoces aymaras en ultramar. Pero una coordinación sólida y estable entre todas estas instancias y con las organizaciones locales de base es una tarea todavía pendiente.

\section{Preguntas y constataciones}

A la luz de lo analizado en este trabajo, ¿podemos hablar de una nación aymara que atraviesa las fronteras de los tres países? Intentemos responder por partes resumiendo, ante todo, lo que hemos podido constatar en estas páginas.

\section{Las evidencias}

Lo primero que salta a la vista es que los tres estados han hecho grandes esfuerzos, algunos muy exitosos, para que la conciencia colectiva de estos aymaras pase antes que nada por la de ser miembros de tal o cual nación-estado y no por la de tener una historia previa o una lengua y cultura aymara común a uno y otro lado de cada frontera. Sólo recientemente hay cierto acercamiento incluso desde los estados en el campo restringido de la lengua, en el contexto de la Educación Intercultural Bilingüe, y cierto reconocimiento aún muy retórico de la condición "multiétnica y pluricultural" de cada estado.

Más allá de las estrategias estatales, los aspectos en que hemos constatado un mayor acercamiento entre los aymaras de los tres países son los siguientes: en la satisfacción de necesidades económicas, laborales o comerciales básicas cuando ésta podía lograrse mejor cruzando la frontera; en la lengua, magnificada sobre todo por las radios; en actividades religiosas, tanto católicas como protestantes; en otras celebraciones y festivales tradicionales; $y$, dentro de un sector más elitista, en eventos varios de orden sobre todo académico y cultural relacionados con el mundo aymara.

Durante el siglo XIX y principios del XX hubo también cierta sintonía y hasta colaboración en sus respectivas luchas contra la expoliación de sus tierras comunales, pero sin llegar nunca a lo que se había logrado a fines de la Colonia, durante el levantamiento de los Amarus y los Kataris. Pero desde los años '30 ha habido una tendencia creciente a que cada sector se concentre sólo en las luchas reivindicativas propias de su contexto estatal, vistas sobre todo desde su condición social campesina. Es decir, ha ido aumentando la inserción de cada grupo en su propia nación-estado. Pese a ello, desde los años '70 ha ido resurgiendo la conciencia "aymara", primero en Bolivia, y de ahí también en los otros países.

Esta nueva conciencia, iha logrado recuperar la conciencia de "aymaridad" a un nivel supraestatal o interestatal? Distingamos entre las bases y los grupos de élite, a los que a veces se ha llamado la "intelligentsia" aymara.

En las bases, ciertamente hay cierta conciencia y cierto sentido de hermandad, siquiera por la lengua, compartida y magnificada por algunas radios. Pero si profundizamos para averiguar si existe además un proyecto histórico y político común, sólo podemos hablar de un potencial todavía no muy actualizado. Adaptando la terminología marxista de clase social, existen los elementos para poder hablar de una nación en sí, pero en el conjunto de los tres países no podemos afirmar todavía que exista ya una nación aymara para sí. ${ }^{29}$ Ciertamente, existe una conciencia de compartir una misma identidad social y cultural básica, pero no hay todavía una suficiente aspiración y voluntad colectiva y explícita para que esta identidad común sea públicamente reconocida por los demás ni una organización adecuada para este fin. Hay embriones para ello, más o menos fuertes según el país y la región, y sectores organizados en que sí existe esta conciencia y voluntad; pero no es aún algo generalizable.

\section{Nación aymara en sí}

Entre los elementos objetivos o en sí, que nos podrían indicar la posibilidad de que se llegue a alcanzar tal conciencia para sí, podemos mencionar los

\footnotetext{
29 En rigor conceptual, en el momento de declararse la Independencia, ni tal vez varias décadas después, en muchos estamentos sociales no existía tampoco una conciencia colectiva de nación peruana, boliviana o chilena para sí, pese al impacto concientizador de las guerras de la Independencia. El proceso de identificación nacional es algo siempre lento, inicialmente catalizado por determinados sectores (Anderson 1991).
} 
siguientes: en las comunidades rurales aymaras de los tres países persiste una cosmovisión y cultura simbólica de fondo bastante común, dentro de sus naturales variantes locales. Casi todos mantienen una referencia permanente a la naturaleza como fuente de vida y llena de vida. La Pacha Mama o Madre Tierra, a igual que los cerros protectores, con denominaciones diversas según la región, sigue siendo objeto de cariño y a la vez de temor reverencial que origina diversos ritos y ofrendas. Es también muy común el sentido de reciprocidad en las relaciones familiares y entre familias, aunque la organización global de cada comunidad sea distinta; conceptos como ayllu, ayni y otros muchos son parte de un acervo cultural reconocido y apreciado por todos como común y propio. Hay que subrayar, con todo, que elementos simbólicos como los mencionados no son exclusivos del pueblo aymara sino compartidos también por el pueblo quechua, otros menores como los uru chipayas, e incluso por algunos grupos andinos que ahora son de habla castellana. Es decir, los elementos de la cultura simbólica en sí podrían conducir incluso a una conciencia de nación andina, expresada en varias lenguas.

Lo que entonces sigue añadiendo una especificidad más aymara, dentro del común denominador andino, es sobre todo la lengua. Este elemento cultural es ahora, en algunos pueblos y naciones modernas, uno de los emblemas más visibles de una identidad común. El idioma aymara sigue muy vivo y sin problemas dialectales insalvables para la mutua comprensión. Las cada vez más numerosas radios aymaras lo atestiguan y lo refuerzan. Algunas antologías recientes de literatura aymara refuerzan además el carácter interestatal de este rasgo compartido (Albó y Layme 1992, Ayala 1994).

Otro elemento de potencial importancia es el territorio común, con todo su trasfondo de historia común. Muchos kataristas e indianistas lo identifican con el antiguo Qullasuyu (una de las cuatro partes del Tawantinsuyu) y, dentro de él, todos subrayan la importancia de viejos centros ceremoniales, muy particularmente en las actuales ruinas de Tiwanaku. Hay con todo aquí, como hemos visto al principio de este trabajo, una clara evolución a través de los siglos, por la que se han ido creando desfases entre el territorio que podríamos llamar histórico y el que ahora es ocupado por gente de habla aymara.

La pertenencia a diversos países y regiones, tanto socioeconómicas como ecológicas, es una fuente indudable de diferencias. Lo hemos visto en las páginas anteriores. Pero al nivel simbólico, tan fundamental para crear un sentido de identidad colectiva, lo que más diferencia internamente a diversos sectores aymaras no es tanto el país o región de adscripción sino la mayor o menor influencia de algunos grupos protestantes fundamentalistas, demasiado propensos a ver algo diabólico en toda creencia y rito ancestral. Esta presencia puede llegar a destruir incluso la identidad y solidaridad más básica, en el seno de la pequeña comunidad local. Pero --a diferencia de lo que ocurre, por ejemplo en Guatemala-- esto último no es lo más común. Donde este riesgo parece ser más real es en algunas comunidades de altura de Chile. Cuando la mayor parte de una comunidad comparte una misma religión evangélica, suele seguir encontrando sus modos para adaptar sus códigos culturales a esta situación. En cambio, cuando la división religiosa separa en grupos competitivos a los miembros de una misma comunidad, el riesgo es mayor; aunque, si hay márgenes de tolerancia mutua, cabe todavía que todos sientan la necesidad de mantener lazos de reciprocidad e intercambio entre sí, y de mantener un gobierno comunal conjunto, evitando que en esos casos deban explicitarse divergencias de tipo religioso.

El hecho de estar en países que han tenido transformaciones y procesos tan distintos influye más en la cultura económica, muy particularmente en el caso chileno como distinto de los otros dos. Hay también significativas variantes en la organización social y política. Pero unas y otras no sólo vienen marcadas por las fronteras internacionales sino también por otros factores ecológicos y socioeconómicos internos de cada país. Tanto en Bolivia como en Perú, por ejemplo, hay notables diferencias internas entre las comunidades del altiplano y de yungas; entre comunidades lacustres, agrícolas o pastoriles, mientras que las que tienen condiciones ecológicas y socioeconómicas semejantes se parecen más entre sí a un lado y otro de la frontera.

\section{Nación aymara para sí}

¿Cómo pasar de ahí a una conciencia para sí de una nación aymara común, que rebalse las fronteras de los tres países? En rigor lógico, nuestra pregunta debe hacerse primero dentro de las fronteras de cada país. ¿Puede hablarse de una nación aymara dentro 
de Bolivia, de Perú o de Chile? Los avances hacia una conciencia de nación aymara para sí parece que son mayores en este ámbito más restringido, con variantes de uno a otro país. Podríamos, incluso, añadir que hay más conciencia de nación entre los aymaras que entre los quechuas, mucho más numerosos pero a la vez más diferenciados y dispersos. Esta conciencia es probablemente mayor en Bolivia que en los otros dos países y, dentro de Bolivia, es sin duda mayor en el ámbito de La Paz que, por ejemplo, en el de Oruro, donde es mínima en la región occidental más cercana a la frontera chilena y está muy disminuida por el avance quechua en la región oriental. En Perú tiene una intensidad intermedia, aunque sigue siendo mayor que la de sus vecinos quechuas, mucho más numerosos. En Chile es aún más débil, aunque allí los acontecimientos de las dos últimas décadas tal vez pueden modificar la situación.

En realidad, llegar a crear una conciencia de nación aymara para sí, consensuada en todos los sectores, es y será siempre un proceso lento, que en este caso debe entrar además en una complementariedad aún mal entendida con la pertenencia a un determinado estado-nación. El concepto de "comunidades imaginadas", aplicado por Anderson (1991) a las naciones estado, vale también para naciones étnicas, como la aymara. En este último caso, es probable que deba pasar además por la estrategia de "inventar" tradiciones, o incluso por el más general proceso de etnogénesis, como los que analizan Hobsbawn y Ranger (1988) y Baud y colaboradores (1996). Veamos algunas situaciones concretas.

En la mayoría de las comunidades rurales, sigue prevaleciendo la conciencia de pertenecer a tal o cual lugar, en círculos más o menos amplios de acuerdo al contrapunto inmediato: otra comunidad, otro pueblo, otra región (Albó 1980), aunque por esa vía se puede llegar también a una identidad aymara si la contraparte no lo es. Esta última situación es menos común en aquellos aymaras que han emigrado a otras partes, sean ciudades o zonas de colonización, y allí pretenden abrirse camino en su nueva situación.

Analicemos en mayor detalle el caso de los aymaras emigrados a la ciudad. La mayoría tiende a diluir su identidad originaria, algo menos en la primera generación, mucho más después de dos o tres generaciones. Sin embargo, en todas partes observamos también variantes aymaras urbanas interesantes. En muchos casos se deben al mantenimiento de lazos sistemáticos con el lugar de origen: más allá de un posible interés económico en los recursos que allí de mantienen, la comunidad viene a ser entonces un importante símbolo emblemático, una especie de santuario de referencia y peregrinaje para ir a "cargar pilas" y mantener el fuego sagrado de la identidad cultural aymara, sobre todo con ocasión de la fiesta patronal, el recuerdo anual de sus difuntos y otras celebraciones semejantes.

Pero estén o no estos lazos, también la ciudad empieza a desarrollar un novedoso estilo aymara urbano, expresado ante todo al interior de las redes sociales de parentesco, origen, solidaridad o prestigio, pero que se extiende también a nuevos festivales, programas radiofónicos, e incluso rituales de origen agropecuario pero adaptados aquí a la necesidad de tener éxito en el trabajo, el estudio o el negocio. Común a todo este estilo aymara urbano es una tensión permanente entre recurrir al pozo de las anteriores experiencias y simbolismos culturales y lanzarse a lo nuevo, entre arraigarse en la identidad previa e ir subiendo socialmente en este nuevo medio urbano. Por eso esta cultura aymara urbana es siempre cambiante, innovadora, con un riesgo permanente de disolverse en los que llevan más tiempo en la ciudad, pero con permanentes oleadas de recién llegados, que tienen más vivos sus lazos con una comunidad de referencia.

Dentro de esta nueva y creciente modalidad de los aymaras urbanos, descubrimos siempre un grupo minoritario pero influyente para el que la ciudad ha servido más bien para reforzar su identidad aymara, sea como reacción al rechazo allí sufrido o simplemente por haber tenido nuevas oportunidades de comprender esta dimensión. Así ha ocurrido, en los tres países, con determinados intelectuales y profesionales, sobre todo aquellos que están en las ramas humanísticas y sociales; los del área económica suelen ser mucho más pragmáticos. Este grupo minoritario que rema contracorriente suele ser una buena cantera de líderes para el resurgimiento aymara. Se ha dado más tal vez en Bolivia y Chile que en el Perú, pues en este último país la tendencia principal de los potenciales líderes es llegar hasta Lima, metrópoli cuyo inmenso tamaño y su alejamiento del territorio ancestral acaba por tragarse a la inmensa mayoría. 
Entonces son ellos los que más fácilmente se convierten en intelectuales "orgánicos" para todo el movimiento, a veces con posturas más ideologizadas o "esencialistas" dentro de la línea que en Bolivia se ha llamado indianista. Naturalmente, son también ellos los que tienen más oportunidades para establecer contactos entre sí a través de las fronteras, tanto entre estos tres países como en eventos indígenas más amplios de carácter internacional.

\section{Más allá de las fronteras}

Pasemos de la perspectiva de las bases a la de aquellos grupos directivos más sensibles a una perspectiva supranacional. Nación aymara, es ciertamente la expresión preferida por los líderes del movimiento aymara, que subrayan así la importancia que tiene para ellos mantener esa identidad, estén en un país u otro.

En realidad, la conciencia para sí a niveles supra o transnacionales tiene tres referentes distintos, que no son mutuamente excluyentes sino más bien complementarios: (a) el de pueblo aymara, que es el que aquí más no interesa; (b) el de una cultura y pueblos andinos, sin diferenciar tanto entre los que hablan distintas lenguas; (c) y finalmente el de pueblos indígenas o indios, con una dimensión continental o incluso mundial.

En términos de énfasis, mi impresión es que esta última es la que más se ha desarrollado, como una oposición al persistente colonialismo interno de cada país y en el conjunto de países de la región. Su principal intento orgánico fue el CISA o Consejo Indio de Sudamérica, al que ya nos hemos referido en varias ocasiones. Constituido en un congreso en Ollantaytambo (Cusco, Perú), en marzo de 1980, era el sucesor y ampliación del Parlamento Indio Americano del Cono Sur (Paraguay 1974) y estaba vinculado al Consejo Mundial de Pueblos Indígenas y a otras instancias de apoyo, como el Tribunal Russell, IGWIA (Dinamarca) e incluso algunas instancias de las Naciones Unidas donde logró ejercer presión, por ejemplo, para avanzar en la proyectada Declaración Universal de los Derechos de los Pueblos Indígenas y en el nuevo Convenio [ahora, 169] de la OIT. En él han jugado un rol clave algunos andinos como Salvador Palomino F. (quechua peruano), Julio Tumiri A. (aymara boliviano) y Ramiro Reynaga B. (quechua boliviano). Su sede funcionó inicialmente en Lima y de ahí pasó a La Paz. Pero ya en su $2^{\circ}$ congreso, reunido en Tiwanaku, Bolivia, en 1983, surgieron ya graves divisiones internas por el liderazgo, que poco a poco acabaron prácticamente con la organización por mucho que algunos de sus antiguos miembros sigan utilizando la sigla. Años después, con ocasión de las celebraciones oficiales de 1992 por el "descubrimiento de América", hubo un notable repunte continental del tema indígena (no necesariamente indianista) --como un movimiento más cercano a las bases que el anterior CISA--, bajo el lema "500 años de resistencia", aprobado en un congreso continental realizado en Quito en 1990. Pero, pasada dicha conmemoración, esta instancia más amplia ha sufrido cierto debilitamiento (al menos desde la perspectiva aymara), aunque sigue convocando a diversos tipos de eventos y es la que más tiene que ver con la deseada "globalización desde abajo". Pero aquí no nos corresponde desarrollar más esta perspectiva más amplia.

En cuanto a las otras dos perspectivas --la específicamente aymara y la más genérica andina-hay un permanente ir y venir entre ambas, sin un claro proyecto histórico en sólo una de las dos vertientes. Algunos insisten mucho más y desde un principio en la dimensión global andina. Así, el PRATEC (Proyecto Andino de Tecnologías Campesinas), que desde el Perú ha logrado ramificaciones y simpatizantes en los otros países, parte de la base común ecológica y técnica para de ahí remontarse a la organización y cosmovisión común. ${ }^{30}$ En el grueso trabajo pionero histórico político del indianista quechua Wankar" "Tawantinsuyu, cinco siglos de guerra qheswaymara contra España" (1978), en el Manifiesto de Tiwanaku (Bolivia, 1973), en el Manifiesto del Movimiento Indio Pedro Vilca Apaza (Perú, 1979) y en otros varios documentos lo "quechuaaymara" se toma también casi siempre como una unidad indiferenciada, contrapuesta a lo español, criollo o europeo. Pero en el proceso de la mayoría de los dirigentes se desarrolla más bien una permanente complementariedad o expansión natural. Por ejemplo, el movimiento por una teología andina, surgió simultáneamente en Perú y Bolivia sobre todo en los aymaras en torno al lago Titicaca, pero caló

30 Una síntesis actualizada de su enfoque, que combina la base eco-económica, social y simbólica, puede encontrarse en PRATEC (1993) y Apfell-Marglin y PRATEC (1997).

31 Ramiro Reynaga B., boliviano, muy conocido a nivel internacional. Es también uno de los principales exponentes de la perspectiva indianista más amplia. 
pronto también en otros pueblos andinos hasta el Ecuador y el norte argentino y chileno, porque todos comparten una cosmovisión religiosa semejante, en medio de mil variedades locales. ${ }^{32}$ Algo parecido ocurre en los planteamientos a la vez políticos y filosóficos de los pensadores aymaras bolivianos Fernando Untoja (1992) y Simón Yampara (1993), quienes partiendo de una perceptiva muy aymara acaban encontrando conceptos sintetizadores comunes a todo el mundo andino, como ayllu (base de la organización social) en el primer caso, pacha ("tiempo y espacio simultáneo”) y pachakutt'i (retorno, reencuentro del hombre con la pacha) en el segundo. Tal expansión tiene pleno sentido por lo que hemos dicho más arriba, al mencionar los elementos culturales comunes que pueden conducir a una conciencia para sí, sobre todo cuando el problema se afronta más allá de las fronteras del propio país. Por todo ello, no resulta fácil encontrar, ni siquiera en estos intelectuales, una propuesta o embrión de proyecto histórico exclusivamente aymara. Todos empiezan denunciando el sistema colonial con mayor o menor profundidad histórica y lujo de detalles. La mayoría usa cierta clave de pasado al plantear su utopía, mostrando las raíces históricas --reales o imaginadas-- de los valores claves para el futuro. ${ }^{33} \mathrm{Al}$ hacer propuestas, enfatizan sobre todo una filosofía y una actitud de respeto y relaciones de reciprocidad con todo el cosmos y con el conjunto de la sociedad, con rechazo de toda imposición foránea colonialista. Dentro de ello, más típicamente aymara es el énfasis en un enfoque derivado de la unidad en la dualidad de la pareja hombre-mujer (chachawarmi). En todos estos planteamientos es común apelar a términos y conceptos en aymara, aunque bastantes son comunes a las dos principales lenguas andinas. ${ }^{34}$

En la dimensión política prevalece el discurso reforzador de los grupos internos originarios en ni-

\footnotetext{
32 Jordá (1981) sintetiza sus fases iniciales, en que participaron más algunos no indígenas. Pero versiones más recientes, como la Memoria del II Encuentro de cultura andina y teología (ASETT 1992) muestran una creciente reflexión en manos de los propios andinos, sean quechuas o aymaras, que acaban insertándose también en una corriente más continental de "teología india", así en singular.

33 Este enfoque, común en muchos pueblos conquistados y colonizados, tiene probablemente más fuerza motivadora que esas vagas referencias a un futuro sin raíces en el pasado, más corrientes en el Primer Mundo, pues enfatiza más que lo soñado es posible. Quienes lo critican aduciendo que el pasado real no fue tan bello como lo pintan, pierden el elemento clave: aunque expresadas en clave de pasado, se trata de utopías. ¿Es esencial que estas se expresen en clave de futuro?
}

veles concéntricos --(a) aymara, (b) andino, (c) originario o indígena ${ }^{35}$-- y en sus diversas dimensiones e instituciones culturales: territoriales, productivas, sociales. organizativas, jurídicas. religiosas, lingüísticas, de salud, etc. Todos coinciden en plantear mayores o menores márgenes de respeto cultural y autonomía de gestión, pero pocos plantean un estado propio, salvo en expresiones sólo retóricas. Más común es dentro de los respectivos estados. Una fórmula que ha ido ganando adeptos es la de transformar los actuales estados excluyentes en "un estado plurinacional", en que quepan a pie de igualdad los sectores criollos y cada uno de los pueblos originarios. En esto hay un significativo contraste con los nacionalismos europeos pasados o presentes. ¿Será sólo por la mayor debilidad demográfica y política de los aymaras (y otros pueblos originarios del continente) o será también porque entre los andinos hay mayores márgenes de tolerancia entre los diferentes?

Muchos hacen referencia a un territorio común que podría servir de base para una utópica sociedad aymara o andina. Pero hay aquí variantes, según lo orígenes: si los que hablan son aymaras bolivianos o peruanos, es más frecuente que hablen de Qullasuyu (que abarca también a pueblos actualmente quechuas); si son quechuas peruanos, prefieren hablar del Tawantinsuyu centrado en el Cusco, incluyendo sus cuatro suyus; y si son quechuas ecuatorianos o aymaras chilenos más fácilmente prescinden de estas referencias territoriales cuyo eje central histórico queda ahora fuera de sus actuales países.

Ha ganado gran vigencia en todas partes, como el principal símbolo identificador, la wiphala o bandera propia, masivamente utilizada en todo tipo de eventos. También en ella hay variantes, según grupos y países. La versión inicialmente popularizada

34 Un análisis del glosario incluido en la Memoria del III Congreso Amáutico reunido en La Paz en 1992 muestra 43 términos sólo aymaras, otros 29 son comunes al quechua y al aymara, 11 sólo quechuas, 7 castellanos y 9 de otros orígenes andinos, para identificar a otras tantas unidades étnicas sobre todo andinas precoloniales.

35 Los aymaras (y otros andinos) prefieren en general el término "originario", que fue propuesto por ellos mismos y no ha llegado a ser subvaluado con connotaciones despectivas (como indígena o indio) por parte de los sectores dominantes. Los otros dos términos no tienen una aceptación tan general: "indio" sólo lo usan los indianistas; e "indígena", aquellos que, con cierto pragmatismo, ven que la comunidad internacional también lo usa para defender los derechos de estos pueblos. 
por los aymaras bolivianos consiste en un tablero de 7 cuadros por lado y siete colores en diagonal. ${ }^{36}$ Si el color de la diagonal central es el blanco, se dice que es la bandera aymara; si es verde, es en cambio la del Tawantinsuyu... Se ha elaborado también otra variante tipo escudo, inspirada en la cruz andina, que aparece en Tiwanaku y otras ruinas precoloniales. La wiphala cusqueña, que se considera bandera del Tawantinsuyu, es una bandera con siete franjas rectangulares de otros tantos colores. Una u otra versión se ha difundido rápidamente. La cusqueña, ha sido también adoptada por los quechuas del Ecuador. La versión aymara ha trascendido a los aymaras de los otros países, pero también a los quechuas de Bolivia, llegando incluso a plantearse que sea un símbolo oficial alternativo de Bolivia.

Este es el panorama objetivo. ¿Serán las convergencias mayores que las divergencias para seguir soñando en una nación aymara que sabe moverse con garbo entre tres estados-nación? ¿Podrá más la identidad basada en la cultura simbólica que las fuerzas centrífugas derivadas de cada estructura estatal?

Desde una perspectiva humanista y ética parece que vale la pena seguir intentando un enfoque pluricultural dentro de cada estado y el fortalecimiento de identidades culturales ahora desgarradas por la intolerancia entre estados "soberanos". Aunque a primera vista parezca contradictorio, la emergencia de nuevos movimientos étnicos incluso interestatales y de nuevas normas legales "multiétnicas y pluriculturales" en diversas partes del mundo, tal vez tenga que ver también con otra coyuntura actual: la globalización. En efecto, ésta debilita la ficticia autosuficiencia absorbente de cada estado-nación con lo que, quizás sin haberlo pretendido, puede también facilitar el resurgimiento de otras identidades soterradas. Si todo ello ocurre dentro de un ambiente de complementariedad y mutua tolerancia entre los distintos, puede que sea bienvenido. En este caso, los aymaras, quechuas, guaraníes, etc. y los diversos estados en que se in-

36 El sociólogo e indianista aymara Inka Waskar [Germán, o Kara] Chukiwanka (1993) realizó un elaborado trabajo interpretativo de esta wiphala, vinculándola a un posible calendario lunar.

37 Resumimos aquí algunos datos básicos de Sandóval y Albó (1978). sertan podrían dar incluso una lección a las viejas naciones europeas.

\section{ANEXO. El singular caso de Ojje}

Concluiremos este panorama con una referencia al caso peculiar de Santiago de Ojje [en rigor lingüístico, Uxi], una comunidad originaria a orillas del lago. ${ }^{37}$ La primera delimitación internacional de la frontera entre Perú y Bolivia asignó inicialmente esta comunidad, ubicada en la boliviana península de Copacabana, al territorio peruano, mientras que otra comunidad, llamada Tapojje [Tapuxi], ubicada ya en el istmo peruano, quedó boliviana. Al menos desde principios de este siglo hubo diversas conversaciones entre las respectivas cancillerías y finalmente en 1938 se hizo un canje por el que Ojje pasaba a Bolivia y Tapojje al Perú. Una vez más, este reajuste se hizo a altos niveles sin consultar a los interesados y, como resultado, la comunidad Santiago de Ojje quedó internamente partida por la frontera pues su parte en tierra firme quedó boliviana pero dos islas que son parte integral de ella quedaron peruanas.

Los relatos y testimonios de la época previa al reajuste de fronteras muestran en Ojje un intercambio permanente a ambos lados de la frontera: entre familias, para pequeños contrabandos, para trabajos, fiestas y también conflictos entre comunidades colindantes. La comunidad o ayllu de Ojje se sentía marginada por estar en el último extremo de su país, y debía cumplir onerosas obligaciones de dependencia, como servicios públicos y presteríos en el pueblo mestizo de Yunguyo, ubicado a más de $20 \mathrm{~km}$ al otro lado de la bahía. Pero la situación fronteriza servía también de válvula de escape cuando surgía cualquier problema. Ya en aquellos tiempos la cercana ciudad de La Paz atraía a muchos ojjeños para trabajar o estudiar, mientras que --por el lado de Puno-- Ojje recibió también el influjo de las misiones evangélicas a que nos hemos referido más arriba.

Durante la guerra del Chaco hubo al menos 15 comunarios que se presentaron como voluntarios aun siendo peruanos y ello es hasta ahora timbre de gloria de la comunidad cuando se compara con otras vecinas que siendo bolivianas tuvieron menos combatientes. Nos sospechamos que la motivación era hacer méritos para poder circular y quizás asentarse en un lugar más céntrico del vecino país. 
Pero al poco tiempo se realizó ya el cambio de fronteras y Ojje quedó boliviano. Con ello acabó su dependencia de Yunguyo pero empezó otra situación semejante con relación al pueblo boliviano de San Pedro de Tiquina.

Pero el principal atractivo de la nueva condición siguió siendo la céntrica ciudad de La Paz. Aumentó la migración laboral a ella, sobre todo como panaderos (¿por la facilidad de tener harina peruana?) y pronto se añadió una dimensión más política, como mecanismo para lograr beneficios para su comunidad que previamente había tenido una situación tan marginal. Ya en 1945 esos neo-bolivianos participaron en el I Congreso Indigenal que convocó el presidente Villarroel y a los pocos meses formaron el "sindicato agrícola de Ojje", el primero que se creaba en toda la península, aunque su sede funcionaba en la ciudad. Por entonces ya había unos 50 ojjeños residentes en la ciudad, pero con un pie en la comunidad para los momentos de mayor actividad agrícola. Este sindicato fue la base para que se organizaran en el campo deportivo y desde 1947 como "Centro de Acción Ojje", iniciando un estilo de mediación ante autoridades, partidos e instituciones de la ciudad en beneficio de su comunidad. Cuando llegó la revolución del MNR en 1952, a través de esos intermediarios urbanos, los ojjeños se involucraron también en este partido y en las medidas del nuevo gobierno, primero como cooperativa (figura entonces prevalente en las comunidades originarias), después para lograr un núcleo escolar y más adelante para lograr el estatus de cantón. Este estilo continúa hasta el día de hoy, con permanentes adaptaciones a los vientos políticos de cada momento.

La anomalía de que las dos islas de la comunidad sigan perteneciendo jurídicamente al Perú no modificó mucho su función productiva. Estas islas no tienen viviendas sino sólo aynuqas, es decir, pastizales y campos de cultivo familiares pero manejados de acuerdo a ritmos rotativos establecidos comunalmente. El gobierno peruano reconoció esta situación de modo que, sin mayor trámite, los comunarios siguen transitando en bote de un lado a otro de la frontera para sus actividades agropecuarias rutinarias. Sin embargo, esta situación originó conflictos sobre todo a partir de la reforma agraria peruana de 1969. Los comunarios de la vecina isla Anapia, que siempre ha sido peruana, empezaron a reclamar para sí estas dos islas alegando que estaban ocupadas por bolivianos. Los ojjeños, para defenderlas, tuvieron que viajar hasta la distante Lima y al final todo quedó como antes, aunque el conflicto sigue rebrotando ocasionalmente.

Lamentablemente carecemos de información sobre lo que ha ocurrido con la contraparte Tapojje --más cercana al pueblo de Yunguyo-- que con el canje pasó de Bolivia al Perú. Pero estos breves apuntes nos ayudan a comprender por una parte el aprovechamiento de una situación fronteriza y, por otra, la fuerte influencia que tiene la adscripción a uno u otro país para ganar o perder en centralidad y, con ello, poder lograr determinados beneficios.

\section{BIBLIOGRAFIA}

ABECIA, V., 1979. Las relaciones internacionales en la historia de Bolivia. La Paz: Amigos del Libro y Academia Nacional de Ciencias de Bolivia.

ALBO, X., 1980. Khitipxtansa. ¿Quiénes somos? La Paz: CIPCA. (Publicado también en América Indígena 39.1:477528 [1979], con el subtítulo "Identidad localista, étnica y clasista en los aymaras de hoy").

--- 1985. De MNRistas a kataristas: campesinado, estado y partidos 1953-1983. Historia Boliviana (Cochabamba) V.1-2: 87-127. (Reproducido en Steve Stern, Ed., Resistance, rebellion, and consciousness in the Andean peasant world. 18th to 20th Centuries. Madison: The University of Wisconsin Press, 1987, pp. 379-419; versión castellana, Lima: Instituto de Estudios Peruanos)
---- 1987. Formación y evolución de lo aymara en el espacio y el tiempo. En Estado y región en los Andes. Cusco: Centro Las Casas, pp. 29-44.

----1988. comp. Raíces de América: El mundo Aymara. Madrid: UNESCO y Alianza Editorial.

---- 1988. Introducción, en Albó, (Ed.)1988. Raíces de América: El mundo Aymara, pp. 21-42.

--.- 1991. El retorno del indio. Revista Andina (Cusco) 9.2: 299-366. Incluye debate.

---1993. ¿...Y de kataristas a MNRistas? La sorprendente y audaz alianza entre aymaras y neoliberales en Bolivia. La Paz: CEDOIN y UNITAS. 
---1995. Bolivia plurilingüe. Guía para planificadores y educadores. La Paz: CIPCA y UNICEF. 2 volúmenes y paquete de mapas.

----1999. Andean people in the twentieth Century. En Salomon y Schwartz (Eds.) Cambridge history of the native peoples of the Americas. Vol. 3, South America. New York \& London: Cambridge University Press, pp. 765-871.

ALBO, X. y F. LAYME., 1992. Literatura aymara. Antología. La Paz: CIPCA, Hisbol y Jayma.

ALBO, X. y J. M. BARNADAS, 1995. La cara india y campesina de nuestra historia. La Paz: CIPCA y Ministerio de Educación. ( $4^{\mathrm{a}}$ ed.).

ALTAMIRANO, T., 1984. Presencia andina en Lima metropolitana: estudio sobre migrantes y clubes de provincianos. Lima: pontificia Universidad Católica del Perú.

ALTAMIRANO, T., 1988. Cultura andina y pobreza: aymaras en Lima metropolitana: estudio sobre migrantes y clubes de provincianos. Lima: pontificia Universidad Católica del Perú.

ANDERSON, B., 1991. Imagined communities. Reflections on the origin and spread of nationalism. London: Verso.

APFFEL-MARGLIN, F. y PRATEC, 1997. eds. The spirit of regeneration: Andean culture confronting Western notions of development. London y New York: Zed Books.

ASETT, 1992. Memoria del II encuentro ecuménico de cultura andina y teología, Viacha, Bolivia. Quito: Abya Yala.

AYALA, J. L., 1994. Literatura aymara. Puno. (Ms inédito). Baud, Michiel, Kees Koonings, Geert Oostindie, Arij Ouweneel y Patricio Silva. 1996. Etnicidad como estrategia en América Latina y el Caribe. Quito: Abya Yala.

BARNADAS, J. M. 1989. Es muy sencillo: Llâmenle Charcas. La Paz: Juventud.

CHIRINOS, A. y C. SCHWAGER, 1997. Mapas linguiísticos del Perú, GTZ, CADEP, DED, Cuzco, Perú.

BELLEZA, N. 1995. Vocabulario jacaru-castellano, castellano-jacaru. Cusco: Centro Bartolomé Las Casas.

BOUYSSE-CASSAGNE, T., 1987. La identidad aymara. Aproximación histórica (siglo XV, siglo XVI). La Paz: Hisbol.

CASTRO, M., 1992. El manejo del agua en poblaciones aymaras y atacameñas de Chile: organización, conflictos y legislación. Santiago: Universidad de Chile.

BAUD, M., K. KOONINGS, G. OOSTINDE, A. OUWENEEL y P. SILVA, 1996. Etnicidad como estrategia en América Latina y el Caribe, Abya Yala, Quito, Ecuador.

CHOQUE C., R., 1985. Sociedad República del Qullasuyu (1930). Boletín Chitakolla (La Paz), $\mathrm{n}^{\circ} 25$.

CHOQUE C., R., 2001 Ms. En preparación. Jesús de Machaqa, la marka rebelde. Vol. I. Cinco siglos de historia. La Paz: CIPCA. Manuscrito en preparación.
CHOQUE C., R. y E. TICONA, 1996. Jesús de Machaqa, la marka rebelde. Vol. 2. Sublevación y masacre de 1921. La Paz: CIPCA y CEDOIN.

CHUKIWANKA, K., 1989. [Germán]. El guerrero Rumimaki, 1914-1915. Llallawa, Tawantinsuyu.

CHUKIWANKA, K., 1993. [Germán], Wiphala comunitaria. En Encuentro de Estudios Bolivianos, Cochabamba, julio 1993. (Reproducido también como folleto y en almanaques aymaras.

CISA (Consejo Indio de Sudamérica), 1980. Primer congreso de movimientos indios de Sudamérica, Ollantaytambo (Cuzco - Perú), 27 de febrero - 3 de marzo 1980. París: Ediciones MITKA.

CISA (Consejo Indio de Sudamérica), 1998. Estatuto del Consejo Indio de Sudamérica CISA. Isla Taquile, Puno, Perú, 3031 de enero y $1^{\circ}$ de febrero de 1998.

CONDARCO, R., 1982. Zárate, el "temible" Willka. La Paz: Imprenta Renovación. $2^{\mathrm{a}}$ ed. ampliada.

DEGREGORI, C. I., 1995. Etnicidad y gobernabilidad democrática en América Latina: una reflexión desde dos países centroandinos. Ponencia presentada al seminario Faultlines of Democratic Governance in the Americas, Nort-South Center, University of Miami. (Ms.)

DESCO , 1989. Violencia política en el Perú, 1980-1989. Lima: DESCO, Centro de Estudios y Promoción del Desarrollo.

ECUADOR, 1998. Constitución politica de la República del Ecuador.

FERREL, M. A., 1996. Textos aimaras en Guaman Poma. Revista Andina (Cusco) 14.2: 413-455.

GOW, R., 1981. Yawar mayu: Revolution in the Southern Andes 1860-1980. Madison: University of Wisconsin. (Tesis doctoral inédita).

GUERRERO, B., 1994. A Dios rogando... Los pentecostales en la sociedad aymara del Norte Grande de Chile. Amsterdam: VU University Press.

HAZEN, D., 1974. Government policy and the Indian problem in Southern Peru, 1900-1955. New Haven, Conn.: Yale University. Tesis doctoral inédita.

HIDALGO, J., 1986. Indian society in Arica, Tarapaca and Atacama, 1750-1793, and its response to the rebellion of Tupac Amaru. London: University of London. (Tesis doctoral inédita).

HOBSBAWM, E. y TERENCE R., 1988. eds. The invention of tradition. London: Cambridge University Press.

HURTADO, J., 1986. El katarismo. La Paz: Hisbol.

JORDA, E., 1981. La cosmovisión aymara en el diálogo de la fe: Teología desde el Titicaca. Lima: Facultad de Teología Pontificia y Civil de Lima. (3 vols.). 
KLEIN, H., 1982. Bolivia: the evolution of a multi-ethnic society. New York: Oxford University Press.

LLANQUE, D., 1981. La historia del pueblo aymara. En CIED, ed. Acerca de la historia y el universo aymara. Lima: Centro de Información, Estudios y Documentación, pp. 11-33.

MAMANI, B. y J. VILCA, 1989. La legislación de aguas en Chile y sus consecuencias destructivas para la comunidad y cultura aymara. En La visión india: Tierra, cultura, lengua $y$ derechos humanos. Ponencias del $46^{\circ}$ Congreso Internacional de Americanistas, Amsterdarn, 1988. Leiden, pp. 4561

MAMANI C., C., 1991. Taraqu 1866-1935. Masacre, guerra y renovación en la biografía de Eduardo L. Nina Qhispi. La Paz: Aruwiyiri.

MANRIQUE, N., 1981. Campesinado y nación: Las guerrillas indigenas en la guerra con Chile. Lima: CIC-Ital Perú.

MANIFIESTO DE TIAHUANACU, 1973. La Paz. (Mimeografiado. Reproducido, entre otros, en Hurtado, 1986).

MOVIMIENTO INDIO PEDRO VILCA APAZA, 1979. Manifiesto. En Pueblo Indio 1981.

MORIN, F, 1983. L'indianité comme nation contre l'État. En L'indianité au Pérou. Mythe ou réalité? Toulouse: GRAL CNRS.

O'PHELAN, S., 1995. La gran rebelión de los Andes: De Tupac Amaru a Tupac Katari. Cusco: Centro Bartolomé Las Casas.

PACHECO, D., 1992. El indianismo y los indios contemporáneos en Bolivia. La Paz: Hisbol y MUSEF.

PARLAMENTO DEL PUEBLO AYMARA, 1996. Primer gran parlamento de la nación aymara (Aymar jach'a ulaqa). Taipiqala Tripartito, 15 y 16 de julio.

PARLAMENTO DEL PUEBLO AYMARA, 1996. Convocatoria a la IV asamblea ordinaria en Taipiqala Tripartito, 5 de julio 1998

POZZI-ESCOT, I., 1998. El multilingüismo en el Perú. Cusco y Cochabamba: Centro Bartolomé Las Casas y PROEIB.

PRATEC. 1993. Afirmación cultural andina. Lima: Proyecto Andino de Tecnología Campesina.
PUEBLO INDIO. Vocero del Consejo Indio de Sudamérica. Lima. $\mathbf{N}^{\circ} 1$ (setiembre octubre de 1981) y Suplemento ideopolítico, noviembre 1982 .

RIVERA, S., 1991. "Pedimos la revisión de límites": Un episodio de incomunicación de castas en el movimiento de caciques-apoderados de los Andes bolivianos 1919-1921. En Segundo Moreno y Frank Salomon, comp., Reproducción y transformación de las sociedades andinas, siglos XVI-XX. Quito: Abya Yala, t. , pp. 349-693.

RIVIERE, G., 1988. Cambios sociales y pentecostalismo en una comunidad aymara. Fe y Pueblo (La Paz) 14: 24-30.

SAIGNES, T., 1978. De la filiation a la résidence: Les ethnies dans les vallées de Larecaja. Annales (París) 33e anneé 5-6: 1160-1181.

SANDOVAL, G., X. ALBO y T. GREAVES, 1987. Chukiyawu, la cara aymara de La Paz. Vol. IV, Nuevos lazos con el campo. La Paz: CIPCA.

SANDOVAL, G. y X. ALBO, 1978. Ojje por encima de todo. La Paz: CIPCA

STROEBELE-GREGOR, J., 1989. Indios de piel blanca: Evangelistas fundamentalistas en Chukiyawu. La Paz: Hisbol.

TICONA, E. y X. ALBO, 1997. Jesús de Machaqa, la marka rebelde. Vol. 2. La lucha por el poder comunal. La Paz: CIPCA.

UNTOJA, F., 1992. Retorno al ayllu. I. La Paz: CADA

VAN KESSEL, J., 1992. Holocausto al progreso. Los aymarás de Tarapacá. La Paz: Hisbol. ( $1^{a}$ ed., Amsterdam, CEDLA).

WANKAR [RAMIRO REYNAGA B.], 1978. Tawantinsuyu. Cinco siglos de guerra qheswaymara contra España. La Paz: Centro de Coordinación y Promoción Campesina Mink'a. (Entre otras reediciones revisadas, ver 1492-1992, Palabra india, Ed. Contracanto, Madrid, 1989).

YAMPARA, S (Ed)., 1993. Naciones autóctona originarias: Vivir-convivir en tolerancia y diferencia. 3er Seminario amáutico del área andina pre y post V Centenario. La Paz: CADA (Centro Andino de Desarrollo Agropecuario).

----1995. Pachakutt'i - Kandiri en el Paytiti. Reencuentro entre la la búsqueda y retorno o la armonía original. La Paz: CADA. 
